\title{
A PRODUÇÃO CIENTÍFICA SOBRE A INTERDISCIPLINARIDADE: UMA REVISÃO INTEGRATIVA $^{1}$
}

\author{
GENÁRIO DOS SANTOS ${ }^{2}$ \\ ORCID: 0000-0001-9481-570X \\ MARIA THEREZA ÁVILA DANTAS COELHO 3 \\ ORCID: 0000-0001-7857-7473 \\ SÉRGIO AUGUSTO FRANCO FERNANDES ${ }^{4}$ \\ ORCID: 0000-0002-6046-1269
}

\begin{abstract}
RESUMO: Neste artigo discute-se a interdisciplinaridade e suas concepções, métodos e obstáculos, tanto na pesquisa científica quanto no ensino superior contemporâneo, levando-se em consideração uma relevante produção existente sobre o tema. Com o intuito de redimensionar e melhor compreender o debate atual sobre a interdisciplinaridade, as ideias dos principais teóricos, publicadas nos últimos cinco anos, são analisadas, apresentando conclusões sobre as concepções e os obstáculos que se configuram, hoje, como os mais relevantes na teoria e na prática interdisciplinar. Trata-se, pois, de uma revisão integrativa, de natureza descritiva. $\mathrm{O}$ destaque é dado, sobretudo, à multiplicidade de saberes interdisciplinares, derivados da complexidade do ser humano, do seu pensamento, da sua natureza e do mundo hodierno. Os resultados evidenciam, portanto, o caráter polissêmico da interdisciplinaridade, reafirmando a sua natureza dinâmica e reflexiva. Os obstáculos encontrados - institucionais, relacionados aos sujeitos e epistemológicos - revelam os desafios para a sua prática. Avançar é uma necessidade para as suas múltiplas possibilidades de realizações.
\end{abstract}

Palavras-chave: interdisciplinaridade, educação superior, formação de conceito.

\section{THE SCIENTIFIC PRODUCTION ABOUT INTERDISCIPLINARITY: AN INTEGRATIVE REVIEW}

\footnotetext{
ABSTRACT: This article discusses interdisciplinarity and its conceptions, methods and obstacles, both in scientific research and in contemporary higher education, taking into account a relevant existing production on the subject. In order to resize and better understand the current

${ }^{1}$ Pesquisa desenvolvida com o apoio da Fundação de Amparo à Pesquisa no Estado da Bahia - FAPESB, através de Bolsa de Estudo.

${ }^{2}$ Universidade Federal da Bahia (PPG-EISU). Salvador, BA, Brasil. < genarioartes@hotmail.com>

${ }^{3}$ Universidade Federal da Bahia. Salvador, BA, Brasil. <maria.thereza@ufba.br>

${ }^{4}$ Universidade Federal do Recôncavo da Bahia. Salvador, BA, Brasil. <sergioaffernandes@gmail.com> Educação em Revista|Belo Horizonte|v.36|e226532|2020
} 
debate on interdisciplinarity, the ideas of the main theoreticians published in the last five years are analyzed, presenting conclusions about conceptions and obstacles that are the most relevant in theory and in interdisciplinary practice nowadays. It is, therefore, an integrative review, of a descriptive nature. Particular emphasis is given to the multiplicity of interdisciplinary knowledge derived from the complexity of the human being, his thinking, his nature and the world today. The results show, therefore, the polysemic character of interdisciplinarity, reaffirming its dynamic and reflexive nature. The obstacles encountered - institutional, people-related, and epistemological - reveal the challenges to their practice. Moving forward is a necessity for its multiple achievement possibilities.

Keywords: interdisciplinarity, higher education, concept formation.

\section{LA PRODUCCIÓN CIENTÍFICA SOBRE INTERDISCIPLINARIEDAD: UNA REVISIÓN INTEGRADORA}

RESUMEN: Este artículo discute la interdisciplinariedad y sus concepciones, métodos y obstáculos, tanto en la investigación científica como en la enseñanza superior contemporánea, considerándose una producción relevante existente sobre el tema. Con el propósito de redimensionar y comprender mejor el debate actual sobre la interdisciplinariedad, se analizan las ideas de los principales teóricos, publicadas en los últimos cinco años, presentando conclusiones sobre concepciones y obstáculos que se configuran hoy como los más relevantes en la teoría y en la práctica interdisciplinar. Así, se trata de una revisión integradora de naturaleza descriptiva en la que se destaca, sobre todo, la multiplicidad de saberes interdisciplinares derivados de la complejidad del ser humano, de su pensamiento, de su naturaleza y del mundo moderno. Los resultados evidencian, por lo tanto, el carácter polisémico de la interdisciplinariedad reafirmando su naturaleza dinámica y reflexiva. Los obstáculos encontrados - institucionales, relativos a los sujetos, epistemológicos - revelan los desafíos para su práctica. Avanzar es una necesidad para sus múltiples posibilidades de realización.

Palabras clave: Interdisciplinariedad, Educación Superior, Formación de conceptos.

\section{INTRODUÇÃO}

Discussões sobre a interdisciplinaridade têm conquistado cada vez mais espaço nas pesquisas científicas de graduação e pós-graduação, sobretudo nas ciências humanas e sociais (LIMA \& CORTES, 2013). De acordo com o Documento de Área 45, da Coordenação de Aperfeiçoamento de Pessoal de Nível Superior (CAPES), os programas de pós-graduação interdisciplinares são os que mais têm crescido no Brasil, nos últimos cinco anos (CAPES, 2019). Dada a importância e crescimento do saber/fazer interdisciplinar, faz-se necessário compreender os avanços dos estudos relacionados a essa temática, dando destaque às concepções e aos obstáculos que essa forma de produção de conhecimento tem enfrentado. 
Os debates disponíveis, atualmente, sobre a interdisciplinaridade, refletem as novas tendências e necessidades de produção do conhecimento, principalmente a partir da propagação da "teoria do pensamento complexo", de Edgar Morin (2006), além das novas dinâmicas e urgências do mercado de trabalho que requer saberes interdisciplinares. De acordo com Morin (2003), é importante que se ultrapasse o conhecimento disciplinar, disjuntivo e se avance para as práticas interdisciplinares na produção do saber como forma de adequação aos novos desafios das sociedades contemporâneas e da complexidade do pensamento.

Para Japiassu (1976), a 'Interdisciplinaridade' é um conceito polissêmico que contempla, ao menos, duas distintas dimensões, a saber: a teórica, que busca identificar e elaborar uma base de conceitos pertinentes que correspondam de modo satisfatório à produção de saberes estruturados, capazes de dialogar e, ao mesmo tempo, se diferenciar das demais formas de produção do conhecimento; e a prática, que demanda profundas reflexões para além das questões epistemológicas, pois se vincula às atitudes dos indivíduos, com o intuito de promover melhores respostas e soluções para os mais diversificados problemas do nosso mundo atual.

Nossos estudos nos permitiram verificar a existência da necessidade de melhor explorar e discutir as concepções que permeiam essa nova forma de produção de saberes, visto ser ainda comum a prática científica unilateral, sobretudo aquela que sustenta os modelos de formação no país, pautada no que se conhece como visão disciplinar dos conteúdos. É importante ressaltar que a prática da interdisciplinaridade não pretende negar os saberes disciplinares, mas, sim, complementá-los e ampliá-los (PHILIPPI \& FERNANDES, 2015). Essa conjunção de saberes é que vai possibilitar, na prática, a efetivação da complexidade do pensamento, dando conta dos fenômenos complexos e da ampliação das experiências teóricopráticas interdisciplinares, que envolvem múltiplos saberes.

Para Morin (2003), as especializações do conhecimento terminam por separar os objetos entre si, afastando-os do contexto do qual fazem parte; por isso, exige-se que as pesquisas interdisciplinares concebam os elos que unem tais conhecimentos, situando-os em seu conjunto e contexto global. Contrário ao paradigma tradicional, o paradigma da complexidade direciona o indivíduo para pensar nos problemas de forma multirreferencial, abordando os diversos domínios dos saberes existentes, sejam eles científicos, filosóficos, teológicos, populares etc. Um caminho possível está sendo construído pela pedagogia rizomática (LINS, 2005), na qual os saberes produzem conexões múltiplas, atravessando diversas áreas do conhecimento. De forma contrária à pedagogia monodisciplinar, a pedagogia interdisciplinar busca o conhecimento em sua máxima totalidade, abrangendo os saberes que, de forma dialógica e interacional, convergem e/ou se complementam. Pela dialogicidade, cada campo disciplinar adquire benefícios através do processo interativo e democrático, que trata os problemas de um ponto de vista comum a todas as ciências, ao mesmo tempo em que estes são tratados em situações individuais e concretas em cada ciência (JAPIASSU, 1976).

Uma das principais justificativas desta pesquisa se afirma na polissêmica e complexa compreensão do que vem a ser a interdisciplinaridade, já que cada enfoque depende da linha teórica de quem pretende defini-la. A compreensão epistemológica acerca da interdisciplinaridade ainda é campo de debates ao redor do mundo, promovida por especialistas das mais diversas 
áreas científicas, sobretudo na França e na Inglaterra, onde a interdisciplinaridade foi inicialmente estimulada (FAZENDA, 1995). Porém, mesmo diante desse cenário epistemológico complexo e ainda em construção, alguns países, em especial o Brasil e os Estados Unidos, têm substancialmente caminhado na direção da pesquisa e da formação interdisciplinar dos indivíduos.

De acordo com Carvalho (2003, p. 69), “A contemporaneidade da educação [...] deveria concentrar esforços sintonizados na construção de saberes universalistas, na formação de pensadores capazes de enfrentar os desafios do conhecimento e criar novas formas de entendimento do mundo". Diante dessa realidade, o presente artigo pretende discutir algumas das principais concepções sobre a interdisciplinaridade, assim como também os principais obstáculos que se opõem a essa prática, problematizando-os em seus aspectos teóricos e práticos, sobretudo no contexto do ensino superior contemporâneo. Para ampliar as discussões sobre a interdisciplinaridade e melhor compreendê-la, serão analisadas algumas ideias dos seus principais teóricos, presentes na literatura científica. Por fim, serão apresentadas as conclusões sobre as análises das concepções e dos obstáculos que se configuram na teoria e na prática interdisciplinar.

\section{METODOLOGIA}

Este estudo é uma revisão integrativa da literatura que, segundo Pompeo et al. (2009), caracteriza-se por ser mais abrangente por permitir a inclusão das pesquisas teórica e empírica com diferentes abordagens metodológicas, sejam elas qualitativas ou quantitativas. Conforme Souza et al. (2010, p. 102), essa revisão configura-se como “[...] um método que proporciona a síntese de conhecimentos e a incorporação da aplicabilidade de resultados de estudos significativos na prática.”. Para caracterizar a revisão integrativa, seguimos as seguintes etapas: 1- escolha e definição do tema, do objetivo e da elaboração das questões que norteiam a pesquisa; 2- busca de artigos na literatura, com determinação de parâmetros para a amostragem; 3- definição de critérios para a categorização dos estudos; 4- caracterização e avaliação dos estudos incluídos nos resultados; 5- discussão dos resultados.

Realizou-se, então, uma busca na base de dados Scientific Electronic Library Online (SciELO), por esta abranger publicações nacionais e internacionais, atualizadas, com significativo reconhecimento no âmbito acadêmico e científico. A SciELO disponibiliza textos completos e de livre acesso, contempla um número significativo de publicações referentes à temática da pesquisa e abrange trabalhos também indexados em outras bases de busca, não apenas do Brasil, mas também de Portugal, Espanha, Peru, México, Colômbia, África do Sul, Cuba, Costa Rica, Venezuela e Chile.

Tendo em vista que o foco deste estudo é a interdisciplinaridade em sua relação com a universidade, foram utilizados, para a busca, os seguintes descritores e suas combinações em língua portuguesa: 'Educação Superior e Interdisciplinaridade', 'Interdisciplinaridade e Conceito', 'Docência Interdisciplinar', 'Professor Interdisciplinar', 'Prática Docente Interdisciplinar', 'Atitude Interdisciplinar' e 'Aula Interdisciplinar'. Esses descritores foram testados previamente na base de dados, sendo verificada a existência de artigos que conferiam materiais disponíveis com os termos utilizados. Eles foram traduzidos e também utilizados em espanhol e inglês. (Tabela 1 - abaixo). 
Tabela 01. Trabalhos encontrados na base de dados Scielo.org a partir dos descritores

\begin{tabular}{|l|c|c|c|c|c|c|c|c|}
\hline \multirow{2}{*}{ Descritores } & \multicolumn{4}{|c|}{ Trabalhos encontrados } & \multicolumn{3}{c|}{ Trabalhos selecionados para a revisão } \\
\cline { 2 - 10 } & $\begin{array}{c}\text { Em } \\
\text { português }\end{array}$ & $\begin{array}{c}\text { Em } \\
\text { inglês }\end{array}$ & $\begin{array}{c}\text { Em } \\
\text { espanhol }\end{array}$ & Total & $\begin{array}{c}\text { Em } \\
\text { português }\end{array}$ & $\begin{array}{c}\text { Em } \\
\text { inglês }\end{array}$ & $\begin{array}{c}\text { Em } \\
\text { espanhol }\end{array}$ & Total \\
\hline $\begin{array}{l}\text { Educaçã Superior e } \\
\text { Interdisciplinaridade }\end{array}$ & 15 & 01 & 08 & $\mathbf{2 4}$ & 08 & - & 02 & $\mathbf{1 0}$ \\
\hline $\begin{array}{l}\text { Interdisciplinaridade } \\
\text { e Conceito }\end{array}$ & 16 & 02 & 02 & $\mathbf{2 0}$ & 06 & - & - & $\mathbf{0 6}$ \\
\hline $\begin{array}{l}\text { Docência } \\
\text { Interdisciplinar }\end{array}$ & 08 & - & 03 & $\mathbf{1 1}$ & - & - & 03 & $\mathbf{0 3}$ \\
\hline $\begin{array}{l}\text { Professor } \\
\text { Interdisciplinar }\end{array}$ & 11 & 01 & 02 & $\mathbf{1 4}$ & 04 & - & 01 & 05 \\
\hline $\begin{array}{l}\text { Prática Docente } \\
\text { Interdisciplinar }\end{array}$ & 07 & - & 02 & $\mathbf{0 9}$ & 03 & - & - & 03 \\
\hline $\begin{array}{l}\text { Atitude } \\
\text { Interdisciplinar }\end{array}$ & 04 & - & - & $\mathbf{0 4}$ & 01 & - & - & $\mathbf{0 1}$ \\
\hline Aula Interdisciplinar & 05 & - & 04 & $\mathbf{0 9}$ & 01 & - & - & $\mathbf{0 1}$ \\
\hline \multicolumn{1}{|c|}{ Total } & $\mathbf{2 6}$ & $\mathbf{0 0}$ & $\mathbf{0 8}$ & $\mathbf{9 1}$ & $\mathbf{2 6}$ & $\mathbf{0 0}$ & $\mathbf{0 8}$ & $\mathbf{2 9}$ \\
\hline
\end{tabular}

Fonte: OS AUTORES

Os critérios de inclusão, definidos para a seleção dos artigos, foram os seguintes: artigos 'revisados por pares', completos, que retratam a temática referente à revisão integrativa, publicados em língua portuguesa, espanhola e inglesa no período de 2013 a 2018 - últimos cinco anos -, por se considerar este período como sendo de efervescentes discussões sobre a interdisciplinaridade no cenário nacional, sobretudo pelo crescimento dos cursos ofertados pelo modelo de ciclos - Bacharelados Interdisciplinares -, promovidos por universidades federais em todo o país, e pelo aumento expressivo de programas de pós-graduação interdisciplinares.

A busca ocorreu no dia 10/06/2018, aplicando-se os filtros 'artigo' e 'revisado por pares'. Foram encontrados 91 artigos. Após análise dos títulos e dos resumos, 57 foram excluídos pelos seguintes motivos: 1 - por não atenderem à centralidade da temática de investigação, visto que neles aparecia a palavra 'interdisciplinaridade', mas, no texto como um todo, não havia nenhuma referência teórica ou de estudo sobre a mesma; 2- devido ao critério de duplicidade, que se configura a partir do aparecimento do mesmo artigo com a busca através de dois ou mais descritores. Ao final dessa etapa, 34 artigos foram selecionados para análise completa. Desses 34 artigos selecionados, 25 estavam escritos em Língua Portuguesa e 09 em Língua Espanhola. Após essa última exclusão, 29 artigos foram, então, considerados pertinentes para a pesquisa (Fluxograma 1 - abaixo). Tais artigos serão identificados nos resultados e na discussão como A1, A2, A3 e, assim, sucessivamente.

Fluxograma 1. Seleção de artigos na base SciELO.org

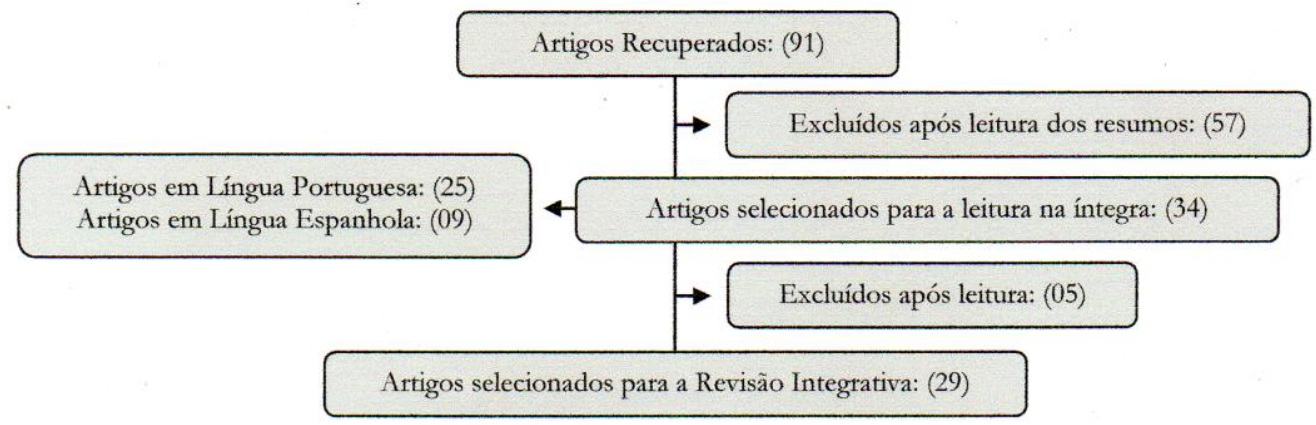

* Elaboração: OS AUTORES 
Após minuciosa leitura de todos esses artigos, 05 foram excluídos por não apresentarem dados correspondentes às categorias de análise de conteúdo previamente elaboradas a partir das leituras prévias de publicações sobre a interdisciplinaridade. As categorias foram: 1. concepsôes de interdisciplinaridade e 2. obstáculos à interdisciplinaridade. A primeira surgiu a partir do momento em que foram identificadas diversas concepções sobre a interdisciplinaridade nos artigos coletados, porém com pouca discussão sobre elas de modo a explorar as suas similaridades e diferenças. A segunda nasceu quando foi percebido que vários obstáculos tinham sido citados pelos autores, também sem discussão, carecendo de reflexões que possibilitassem compreender quais aspectos colaboravam para a existência desses entraves e como minimizá-los.

Posteriormente, procedeu-se à análise categorial de conteúdo sobre a interdisciplinaridade, que "oscila entre os dois polos do rigor da objetividade e da fecundidade da subjetividade” (BARDIN, 2004, p. 7). A categoria concep̧ões de interdisciplinaridade abrangeu os conceitos e as definições apresentadas pelos autores ligadas à pesquisa, ensino ou outra prática interdisciplinar; a categoria obstáculos à interdisciplinaridade, os fatores ou situações que podem ser consideradas como aspectos que dificultam a realização da pesquisa, ensino ou prática científica e/ou pedagógica interdisciplinares.

A análise dos estudos selecionados pautou-se em autores como Fhilippe \& Fernandes, Gattás \& Furegato, Japiassu, Fazenda, Léyourneau, Morin, Piaget e Pombo, sendo que a análise, a interpretação e a síntese das informações foram realizadas de forma descritiva, permitindo observar, quantificar, descrever e classificar os dados. A análise e a apresentação dos resultados ocorreram por agrupamento, a partir das principais semelhanças e diferenças encontradas nos estudos. Reuniu-se, para tanto, conhecimentos diferenciados, produzidos sobre a interdisciplinaridade, trazendo, assim, significativa contribuição para novas reflexões dentro do campo científico e pedagógico-educacional.

\section{RESULTADOS}

Os 29 artigos analisados apresentaram informações fundamentais para a realização deste estudo. Dentre eles, 22 são publicações nacionais (em língua portuguesa) e 7 são publicações internacionais (em língua espanhola), sendo 5 da Colômbia, 1 do Peru e 1 do México. Quanto ao ano de publicação, 3 foram publicados em 2013, 6 em 2014, 4 em 2015, 10 em 2016 e 6 em 2017. Com base nos elementos contidos nos artigos, todos foram classificados como sendo de natureza qualitativa: 3 são análise documental; 4, revisão de literatura; 3, estudos de casos; 4, descritivos e exploratórios; 11, outros tipos de estudos qualitativos e 1, qualitativo e quantitativo. No Quadro 1, abaixo, estão caracterizados os 29 artigos selecionados.

Quadro 1. Caracterização dos 29 artigos selecionados para a revisão sistemática

\begin{tabular}{|c|c|c|c|c|c|c|}
\hline$N^{\mathbf{0}}$ & Autores & $\begin{array}{c}\text { Ano/ } \\
\text { País }\end{array}$ & Periódico & \multicolumn{1}{|c|}{ Título } & \multicolumn{1}{c|}{ Objetivo } \\
\hline A1 & $\begin{array}{c}\text { TAVA- } \\
\text { RES \& } \\
\text { GOMES }\end{array}$ & $\begin{array}{l}2017 \\
\text { Brasil }\end{array}$ & $\begin{array}{c}\text { Educação } \\
\& \\
\text { Sociedade }\end{array}$ & $\begin{array}{l}\text { Fundamentos } \\
\text { epistemológicos da matriz } \\
\text { institucional dos novos } \\
\text { modelos de educação } \\
\text { superior no Brasil: uma } \\
\text { abordagem qualitativa dos } \\
\text { documentos institucionais } \\
\text { da Universidade Federal do } \\
\text { ABC }\end{array}$ & $\begin{array}{l}\text { Refletir sobre a estrutura institucional } \\
\text { que sustenta um novo modelo de } \\
\text { educação superior no Brasil, } \\
\text { particularmente na Universidade Federal } \\
\text { do ABC (UFABC) }\end{array}$ & $\begin{array}{l}\text { Pesq. quali. } \\
\text { documental }\end{array}$ \\
\hline
\end{tabular}


Quadro 1. (Continuação)

\begin{tabular}{|c|c|c|c|c|c|c|}
\hline $\mathbf{N}^{\circ}$ & Autores & $\begin{array}{c}\text { Ano/ } \\
\text { País }\end{array}$ & Periódico & Titulo & Objetivo & Método \\
\hline $\mathrm{A} 2$ & $\begin{array}{l}\text { VASEN } \\
\& \\
\text { VIENNI }\end{array}$ & $\begin{array}{l}2017 \\
\text { Brasil }\end{array}$ & $\begin{array}{l}\text { Revista } \\
\text { Avaliação }\end{array}$ & $\begin{array}{l}\text { La institucionalización de la } \\
\text { interdisciplina en la } \\
\text { universidad } \\
\text { latinoamericana: } \\
\text { experiencias y lecciones de } \\
\text { Uruguay y Argentina }\end{array}$ & $\begin{array}{l}\text { Analisar, comparativamente, dois } \\
\text { espaços institucionais para a pesquisa } \\
\text { interdisciplinar no contexto de duas } \\
\text { universidades latino-americanas: a } \\
\text { Universidade de Buenos Aires (UBA), na } \\
\text { Argentina, e a Universidade da } \\
\text { República (UdelaR), no Uruguai }\end{array}$ & $\begin{array}{l}\text { Pesq. quali. } \\
\text { e } \\
\text { documental }\end{array}$ \\
\hline A3 & $\begin{array}{l}\text { XAVIER } \\
\text { et al }\end{array}$ & $\begin{array}{l}2017 \\
\text { Brasil }\end{array}$ & $\begin{array}{l}\text { Ciência \& } \\
\text { Educação }\end{array}$ & $\begin{array}{l}\text { (Inter)disciplinaridade e } \\
\text { transversalidades: o projeto } \\
\text { de formação superior da } \\
\text { Universidade Federal do } \\
\text { ABC }\end{array}$ & $\begin{array}{l}\text { Compreender como se dão as relações } \\
\text { curriculares no projeto pedagógico e } \\
\text { quais os regimes de verdade } \\
\text { apresentados na idealização e na } \\
\text { execução desse projeto no que trata dos } \\
\text { enunciados de interdisciplinaridade. }\end{array}$ & $\begin{array}{l}\text { Pesq. quali. } \\
\text { e } \\
\text { documental }\end{array}$ \\
\hline $\mathrm{A} 4{ }^{\prime}$ & $\begin{array}{l}\text { JOSÉ et } \\
\text { al. }\end{array}$ & $\begin{array}{l}2014 \\
\text { Brasil }\end{array}$ & $\begin{array}{l}\text { Revista } \\
\text { Ensaio }\end{array}$ & $\begin{array}{l}\text { ENEM, temas } \\
\text { estruturadores e conceitos } \\
\text { unificadores no ensino de } \\
\text { fisica }\end{array}$ & $\begin{array}{l}\text { Investigar as questões e os } \\
\text { conhecimentos relacionados à física } \\
\text { presentes nas provas de Ciências } \\
\text { Naturais e suas Tecnologias nas edições } \\
\text { de } 2009 \text { a } 2012 \text { do Enem }\end{array}$ & $\begin{array}{l}\text { Pesq. } \\
\text { Explorató- } \\
\text { ria }\end{array}$ \\
\hline A5 & $\begin{array}{l}\text { RUEDA } \\
\text { ORTIZ \& } \\
\text { GARCIA }\end{array}$ & $\begin{array}{l}2016 \\
\text { Colôm- } \\
\text { bia }\end{array}$ & Nómadas & $\begin{array}{l}\text { Doctorados en ciencias } \\
\text { sociales: epistemologías y } \\
\text { políticas de inclusión }\end{array}$ & $\begin{array}{l}\text { Analisar os doutorados em ciências } \\
\text { sociais e a política de educação superior } \\
\text { inclusiva na América Latina }\end{array}$ & $\begin{array}{c}\text { Análise } \\
\text { qualitativa }\end{array}$ \\
\hline A 6 & $\begin{array}{l}\text { PIMEN- } \\
\text { TEL et } \\
\text { al. }\end{array}$ & $\begin{array}{l}2015 \\
\text { Brasil }\end{array}$ & $\begin{array}{l}\text { Revista } \\
\text { Brasileira } \\
\text { de } \\
\text { Educação } \\
\text { Médica } \\
\end{array}$ & $\begin{array}{l}\text { Ensino e Aprendizagem em } \\
\text { Estágio Supervisionado: } \\
\text { estágio Integrado em Saúde }\end{array}$ & $\begin{array}{l}\text { Avaliar o processo de ensino- } \\
\text { aprendizagem no estágio supervisionado, } \\
\text { quando realizado com a integração de } \\
\text { estudantes de diversos cursos na área da } \\
\text { saúde }\end{array}$ & $\begin{array}{l}\text { Pesq. quali. } \\
\text { e estudo de } \\
\quad \text { caso } \\
\text { etnográfico }\end{array}$ \\
\hline A7 & $\begin{array}{l}\text { SAAVE } \\
\text { DRA- } \\
\text { CAN- } \\
\text { TOR et al }\end{array}$ & $\begin{array}{l}2015 \\
\text { Colòm- } \\
\text { bia }\end{array}$ & $\begin{array}{l}\text { Educação } \\
\text { \&Educação }\end{array}$ & $\begin{array}{l}\text { Semilleros de investigación: } \\
\text { desarrollos y desafios para } \\
\text { la formación en pregrado }\end{array}$ & $\begin{array}{l}\text { Describir los desarrollos y desafios de } \\
\text { los semilleros de investigación en la } \\
\text { formación de estudiantes de pregrado en } \\
\text { Colombia }\end{array}$ & $\begin{array}{l}\text { Revisão } \\
\text { sistemática } \\
\text { de } \\
\text { literatura }\end{array}$ \\
\hline A8 & $\begin{array}{l}\text { SOUZA } \\
\text { \& } \\
\text { ANDRA- } \\
\text { DE }\end{array}$ & $\begin{array}{l}2014 \\
\text { Brasil }\end{array}$ & $\begin{array}{l}\text { Ciência \& } \\
\text { Saúde } \\
\text { Coletiva }\end{array}$ & $\begin{array}{l}\text { Saúde, meio ambiente e } \\
\text { território: uma discussão } \\
\text { necessária na formação em } \\
\text { saúde }\end{array}$ & $\begin{array}{l}\text { Analisar a interdisciplinaridade entre } \\
\text { Saúde e Meio Ambiente, na graduação } \\
\text { em saúde de instituições públicas de } \\
\text { ensino superior }\end{array}$ & $\begin{array}{l}\text { Pesq. quali. } \\
\text { descritiva e } \\
\text { explorató- } \\
\text { ria }\end{array}$ \\
\hline A9 & $\begin{array}{l}\text { CORRE- } \\
\text { IA et al. }\end{array}$ & $\begin{array}{c}2014 \\
\text { Brasil }\end{array}$ & $\begin{array}{l}\text { Ciência \& } \\
\text { Educação }\end{array}$ & $\begin{array}{l}\text { Nova abordagem para } \\
\text { identificar conexões } \\
\text { disciplinares usando mapas } \\
\text { conceituais: em busca da } \\
\text { interdisciplinaridade no } \\
\text { Ensino Superior }\end{array}$ & $\begin{array}{l}\text { Explorar o mapeamento conceitual (MC) } \\
\text { como forma de identificar pontos de } \\
\text { acoplamento entre as disciplinas Ciências } \\
\text { da Natureza e Psicologia, Educação e } \\
\text { Temas Contemporâneos }\end{array}$ & $\begin{array}{l}\text { Pesq. quali. } \\
\text { de revisão } \\
\quad \text { de } \\
\text { literatura e } \\
\text { de análise } \\
\text { documental }\end{array}$ \\
\hline A10 & $\begin{array}{l}\text { VENTU- } \\
\text { RA \& } \\
\text { LINS }\end{array}$ & $\begin{array}{c}2014 \\
\text { Brasil }\end{array}$ & $\begin{array}{l}\text { Cadernos } \\
\text { de Pesquisa }\end{array}$ & $\begin{array}{l}\text { Educação superior e } \\
\text { complexidade: integtação } \\
\text { entre disciplinas no campo } \\
\text { das relações internacionais }\end{array}$ & $\begin{array}{l}\text { Analisar a integração entre as disciplinas } \\
\text { no campo das relações internacionais }\end{array}$ & $\begin{array}{l}\text { Revisão } \\
\text { crítica da } \\
\text { literatura }\end{array}$ \\
\hline A11 & $\begin{array}{l}\text { FILHO } \\
\text { et al. }\end{array}$ & $\begin{array}{l}2016 \\
\text { Brasil }\end{array}$ & $\begin{array}{l}\text { Revista } \\
\text { Paradigma }\end{array}$ & $\begin{array}{l}\text { Para além do pensamento } \\
\text { domesticado: reflexões } \\
\text { sobre docência e educação } \\
\text { superior no contexto da } \\
\text { saúde }\end{array}$ & $\begin{array}{l}\text { Discutir a educação superior no âmbito } \\
\text { da saúde, vislumbrando demonstrar a } \\
\text { importância de um novo professor, } \\
\text { capaz de colaborar com a construção de } \\
\text { sujeitos preparados para atuar de modo } \\
\text { crítico e reflexivo frente à realidade de } \\
\text { saúde na qual estejam inseridos }\end{array}$ & $\begin{array}{l}\text { Pesq. quali. } \\
\text { de revisão } \\
\text { de } \\
\text { literatura }\end{array}$ \\
\hline $\mathrm{A} 12$ & $\begin{array}{l}\text { COSTA } \\
\& \\
\text { LOUREI } \\
\text {-RO }\end{array}$ & $\begin{array}{l}2017 \\
\text { Brasil }\end{array}$ & $\begin{array}{l}\text { Revista } \\
\text { Katálysis }\end{array}$ & $\begin{array}{l}\text { A interdisciplinaridade em } \\
\text { Paulo Freire: aproximações } \\
\text { político-pedagógicas para a } \\
\text { educação ambiental crítica }\end{array}$ & $\begin{array}{l}\text { Tratar da contribuição pedagógica do } \\
\text { educador brasileiro Paulo Freire na } \\
\text { questão interdisciplinar e sua } \\
\text { convergência para a Educação } \\
\text { Ambiental (EA) Crítica }\end{array}$ & Pesq. quali. \\
\hline A13 & $\begin{array}{l}\text { SANTOS } \\
\text { et al. }\end{array}$ & $\begin{array}{l}2015 \\
\text { Brasil }\end{array}$ & $\begin{array}{l}\text { Revista } \\
\text { Brasileira } \\
\text { de } \\
\text { Educação } \\
\text { Médica }\end{array}$ & $\begin{array}{l}\text { Integralidade e } \\
\text { Interdisciplinaridade na } \\
\text { Formação de Estudantes de } \\
\text { Medicina }\end{array}$ & $\begin{array}{l}\text { Investigar de que forma os alunos de } \\
\text { Medicina estão sendo formados quanto à } \\
\text { integralidade e à interdisciplinaridade }\end{array}$ & $\begin{array}{l}\text { Pesq. } \\
\text { transversal, } \\
\text { exploratóri } \\
\text { a descritiva, } \\
\text { inferencial. } \\
\text { Quali. e } \\
\text { quanti. }\end{array}$ \\
\hline A14 & $\begin{array}{l}\text { CESCO } \\
\text { et al. }\end{array}$ & $\begin{array}{l}2014 \\
\text { Brasil }\end{array}$ & $\begin{array}{c}\text { Revista } \\
\text { Brasileira } \\
\text { de Ciências } \\
\text { Sociais } \\
\end{array}$ & $\begin{array}{l}\text { Interdisciplinaridade, entre } \\
\text { o conceito e a prática: um } \\
\text { estudo de caso }\end{array}$ & $\begin{array}{l}\text { Analisar os resultados alcançados em um } \\
\text { projeto de pesquisa contemplado pela } \\
\text { Capes com uma bolsa Prodoc }\end{array}$ & $\begin{array}{l}\text { Estudo de } \\
\text { caso }\end{array}$ \\
\hline
\end{tabular}


Quadro 1. (Continua)

\begin{tabular}{|c|c|c|c|c|c|c|}
\hline $\mathbf{N}^{\circ}$ & Autores & $\begin{array}{l}\text { Ano/ } \\
\text { País }\end{array}$ & Periódico & Título & Objetivo & Método \\
\hline A15 & $\begin{array}{l}\text { SAN- } \\
\text { CHO \& } \\
\text { SILVA }\end{array}$ & $\begin{array}{l}2013 \\
\text { Brasil }\end{array}$ & $\begin{array}{l}\text { Physis } \\
\text { Revista de } \\
\text { Saúde } \\
\text { Coletiva }\end{array}$ & $\begin{array}{l}\text { Descortinando o acesso aos } \\
\text { serviços de saúde na } \\
\text { perspectiva da } \\
\text { interdisciplinaridade: debate } \\
\text { de ideias }\end{array}$ & $\begin{array}{l}\text { Evidenciar, sob o olhar interdisciplinar } \\
\text { da Economia, Política, Direito e } \\
\text { Socioantropologia, a conformação do } \\
\text { conceito de acesso, particularmente o } \\
\text { relacionado ao serviço de saúde }\end{array}$ & $\begin{array}{c}\text { Pesq. quali. } \\
\text { de revisão } \\
\text { de } \\
\text { literatura }\end{array}$ \\
\hline $\begin{array}{l}\mathrm{A} 16 \\
,\end{array}$ & $\begin{array}{l}\text { WAN- } \\
\text { DER- } \\
\text { LEY }\end{array}$ & $\begin{array}{l}2013 \\
\text { Brasil }\end{array}$ & $\begin{array}{l}\text { Estudos } \\
\text { Avançados }\end{array}$ & $\begin{array}{l}\text { Realismo utópico: o público } \\
\text { e o intertransdisciplinar }\end{array}$ & $\begin{array}{l}\text { Analisar as estratégias do realismo } \\
\text { utópico para compreensão e } \\
\text { enfrentamento das questões da nutrição } \\
\text { e pobreza }\end{array}$ & $\begin{array}{l}\text { Não } \\
\text { apresenta }\end{array}$ \\
\hline A17 & $\begin{array}{l}\text { JODE- } \\
\text { LET }\end{array}$ & $\begin{array}{l}2016 \\
\text { Brasil }\end{array}$ & $\begin{array}{l}\text { Cadernos } \\
\text { de Pesquisa }\end{array}$ & $\begin{array}{l}\text { A representação: noção } \\
\text { transversal, ferramenta da } \\
\text { transdisciplinaridade }\end{array}$ & $\begin{array}{l}\text { Refletir sobre as formas e os princípios } \\
\text { da transdisciplinaridade e sobre a } \\
\text { pertinência de uma noção como a de } \\
\text { representação para o desenvolvimento } \\
\text { de abordagens transdisciplinares }\end{array}$ & $\begin{array}{c}\text { Não } \\
\text { apresenta }\end{array}$ \\
\hline A18 & $\begin{array}{c}\text { MENDO } \\
-\mathrm{ZA}\end{array}$ & $\begin{array}{l}2016 \\
\text { México }\end{array}$ & Sociológica & $\begin{array}{l}\text { La uam-Lerma y su modelo } \\
\text { educativo: lo organizacional } \\
\text { y el ejercicio interdisciplinar } \\
\text { en un espacio universitario }\end{array}$ & $\begin{array}{l}\text { Indagar las condiciones organizacionales } \\
\text { que favorecen o inhiben el ejercicio del } \\
\text { modelo educativo en una institución } \\
\text { universitaria de reciente creación }\end{array}$ & $\begin{array}{c}\text { Não } \\
\text { apresenta }\end{array}$ \\
\hline A19 & $\begin{array}{l}\text { VAR- } \\
\text { GAS- } \\
\text { D'UNIA } \\
\text { M et al }\end{array}$ & $\begin{array}{l}2016 \\
\text { Peru }\end{array}$ & Educación & $\begin{array}{l}\text { Innovación en la docencia } \\
\text { universitaria. Una } \\
\text { propuesta de trabajo } \\
\text { interdisciplinario y co- } \\
\text { laborativo en educación } \\
\text { superior }\end{array}$ & $\begin{array}{l}\text { Apresentar la sistematización de la } \\
\text { implementación de una experiencia de } \\
\text { innovación en la docencia universitaria }\end{array}$ & $\begin{array}{c}\text { Não } \\
\text { apresenta }\end{array}$ \\
\hline A20 & $\begin{array}{l}\text { ARA- } \\
\text { MAN \& } \\
\text { BATIS- } \\
\text { TA }\end{array}$ & $\begin{array}{l}2017 \\
\text { Brasil }\end{array}$ & Bolema & $\begin{array}{l}\text { O Processo de Construção } \\
\text { de Abordagens Históricas } \\
\text { na Formação } \\
\text { Interdisciplinar do } \\
\text { Professor de Matemática }\end{array}$ & $\begin{array}{l}\text { Compreender e explicitar algumas } \\
\text { relações entre os conhecimentos teóricos } \\
\text { e metodológicos advindos da história da } \\
\text { Matemática e a construção dos saberes } \\
\text { interdisciplinares do professor de } \\
\text { Matemática }\end{array}$ & $\begin{array}{l}\text { Pesq. quali. } \\
\text { de natureza } \\
\text { descritiva }\end{array}$ \\
\hline A21 & $\begin{array}{c}\text { KERSCH } \\
\text { \& } \\
\text { MAR- } \\
\text { QUES }\end{array}$ & $\begin{array}{l}2016 \\
\text { Brasil }\end{array}$ & $\begin{array}{l}\text { Trabalhos } \\
\text { em } \\
\text { Linguística } \\
\text { Aplicada }\end{array}$ & $\begin{array}{l}\text { Saímos do cinema de alma } \\
\text { lavada: multiletramentos e } \\
\text { trabalho interdisciplinar na } \\
\text { produção de curtas de } \\
\text { acessibilidade midiática } \\
\end{array}$ & $\begin{array}{l}\text { Discutir como um projeto coletivo, com } \\
\text { um fim específico, pode mobilizar } \\
\text { professores que precisam trabalhar em } \\
\text { pares, desenvolver seus multiletramentos } \\
\text { e construir identidades }\end{array}$ & $\begin{array}{l}\text { Estudo de } \\
\text { caso }\end{array}$ \\
\hline A 22 & $\begin{array}{l}\text { GÓMEZ } \\
\text { GÓMEZ } \\
\text { et al }\end{array}$ & $\begin{array}{c}2015 \\
\text { Colôm- } \\
\text { bia }\end{array}$ & $\begin{array}{l}\text { Praxis \& } \\
\text { Saber }\end{array}$ & $\begin{array}{l}\text { Estilos pedagógicos de } \\
\text { docentes de lafacultad de } \\
\text { educación de la UPTC } \\
\text { en los proyectos pedagógicos } \\
\text { e investigativos I y II }\end{array}$ & $\begin{array}{l}\text { Descobrir e caracterizar os estilos } \\
\text { pedagógicos de professores da } \\
\text { Faculdade de Educação da Universidad } \\
\text { Pedagógica y Tecnológica de Colombia, } \\
\text { no desenvolvimento dos Projetos } \\
\text { Pedagógicos Investigativos I y II, } \\
\text { disciplinas da área interdisciplinar }\end{array}$ & $\begin{array}{l}\text { Pesq. quali. } \\
\text { descritiva e } \\
\text { quantitativa }\end{array}$ \\
\hline A23 & $\begin{array}{l}\text { CASTI- } \\
\text { BLAN- } \\
\text { CO \& } \\
\text { NARDI }\end{array}$ & $\begin{array}{l}2014 \\
\text { Colôm- } \\
\text { bia }\end{array}$ & $\begin{array}{l}\text { Revista } \\
\text { Electrónica } \\
\text { de Investi- } \\
\text { gación en } \\
\text { Educación } \\
\text { e en } \\
\text { Ciencias }\end{array}$ & $\begin{array}{l}\text { Interpretando la estructura } \\
\text { curricular de programas } \\
\text { brasileños de Licenciatura } \\
\text { en Física, a partir de una } \\
\text { perspectiva epistemológica } \\
\text { de la Didáctica de la Física1 }\end{array}$ & $\begin{array}{l}\text { Contribuir para a compreensão da } \\
\text { complexidade ligada à definição e à } \\
\text { prática da "Didática da Física" na } \\
\text { formação inicial de professores }\end{array}$ & $\begin{array}{c}\text { Análise } \\
\text { documental }\end{array}$ \\
\hline A 24 & $\begin{array}{l}\text { SANTOS } \\
\& \\
\text { VALEI- } \\
\text { RAS } \\
\end{array}$ & $\begin{array}{l}2014 \\
\text { Brasil }\end{array}$ & $\begin{array}{c}\text { Revista } \\
\text { Brasileira } \\
\text { de Ensino } \\
\text { de Física }\end{array}$ & $\begin{array}{l}\text { Currículo interdisciplinar } \\
\text { para licenciatura em ciências } \\
\text { da natureza }\end{array}$ & $\begin{array}{l}\text { Descrever uma proposta de currículo } \\
\text { interdisciplinar para a formação de } \\
\text { professores de ciências da natureza }\end{array}$ & $\begin{array}{c}\text { Não } \\
\text { apresenta }\end{array}$ \\
\hline A25 & $\begin{array}{l}\text { SOUSA } \\
\& \\
\text { BASTOS }\end{array}$ & $\begin{array}{l}2016 \\
\text { Brasil }\end{array}$ & $\begin{array}{l}\text { Trabalho, } \\
\text { Educação e } \\
\text { Saúde }\end{array}$ & $\begin{array}{l}\text { Interdisciplinaridade e } \\
\text { formação na área de } \\
\text { farmácia }\end{array}$ & $\begin{array}{l}\text { Desvelar a compreensão de } \\
\text { coordenadores de cursos de graduação } \\
\text { em Farmácia da região Centro-Oeste do } \\
\text { Brasil sobre a interdisciplinaridade na } \\
\text { formação do farmacêutico }\end{array}$ & $\begin{array}{l}\text { Pesq. quali. } \\
\text { fenomeno- } \\
\text { lógica }\end{array}$ \\
\hline A26 & $\begin{array}{l}\text { TOASSI } \\
\text { \& LEW- } \\
\text { GOY }\end{array}$ & $\begin{array}{l}2016 \\
\text { Brasil }\end{array}$ & Interface & $\begin{array}{l}\text { Práticas Integradas em } \\
\text { Saúde I: uma experiência } \\
\text { inovadora de integração } \\
\text { intercurricular e } \\
\text { interdisciplinar }\end{array}$ & $\begin{array}{l}\text { Analisar uma experiência curricular } \\
\text { inovadora chamada 'Práticas Integradas } \\
\text { em Saúde I', proposta pela } \\
\text { Coordenadoria de Saúde da } \\
\text { Universidade Federal do Rio Grande do } \\
\text { Sul }\end{array}$ & $\begin{array}{c}\text { Pesq. } \\
\text { documental }\end{array}$ \\
\hline
\end{tabular}


Quadro 1. (Continuação)

\begin{tabular}{|c|c|c|c|c|c|c|}
\hline $\mathbf{N}^{o}$ & Autores & $\begin{array}{l}\text { Ano/ } \\
\text { País }\end{array}$ & Periódico & Título & Objetivo & Método \\
\hline A27 & $\begin{array}{c}\text { ACEVE- } \\
\text { DORIN- } \\
\text { CÓN \& } \\
\text { FIOREN } \\
\text {-TINI }\end{array}$ & $\begin{array}{c}2016 \\
\text { Colômb } \\
\text { ia }\end{array}$ & $\begin{array}{c}\text { Revista de } \\
\text { la Facultad } \\
\text { de Ciencia } \\
\text { y } \\
\text { Tecnologia }\end{array}$ & $\begin{array}{l}\text { Práticas na formação dos } \\
\text { licenciados em matemática: a } \\
\text { experiência de una prática } \\
\text { interdisciplinar }\end{array}$ & $\begin{array}{l}\text { Apresentar as aproximações feitas } \\
\text { sobre a prática profissional docente, } \\
\text { como uma das formas de prática } \\
\text { social, para compreender as } \\
\text { aprendizagens de um grupo de } \\
\text { estagiários de Licenciatura em } \\
\text { Matemática da Unicamp }\end{array}$ & $\begin{array}{c}\text { Não } \\
\text { apresenta }\end{array}$ \\
\hline A 28 & $\begin{array}{l}\text { STA- } \\
\text { DLER \& } \\
\text { HUS- } \\
\text { SEIN }\end{array}$ & $\begin{array}{l}2017 \\
\text { Brasil }\end{array}$ & $\begin{array}{l}\text { Ciência \& } \\
\text { Educação }\end{array}$ & $\begin{array}{l}\text { O perfil das questões de } \\
\text { ciências naturais do novo } \\
\text { Enem: interdisciplinaridade or } \\
\text { contextualização? }\end{array}$ & $\begin{array}{l}\text { Entender como as avaliações do } \\
\text { Novo Enem apresentam elementos } \\
\text { que remetam às abordagens } \\
\text { contextuais e interdisciplinares }\end{array}$ & $\begin{array}{l}\text { Pesq. de } \\
\text { análise de } \\
\text { conteúdo } \\
\text { categorial }\end{array}$ \\
\hline A 29 & $\begin{array}{l}\text { MALDO } \\
\text { NADO- } \\
\text { TORRES }\end{array}$ & $\begin{array}{l}2016 \\
\text { Brasil }\end{array}$ & $\begin{array}{c}\text { Revista } \\
\text { Sociedade e } \\
\text { Estado }\end{array}$ & $\begin{array}{l}\text { Transdisciplinaridade } \\
\text { e decolonialidade }\end{array}$ & $\begin{array}{l}\text { Identificar a epistemologia adequada } \\
\text { para "estudos étnicos", que identifico } \\
\text { como forma de transdisciplinaridade } \\
\text { decolonial }\end{array}$ & $\begin{array}{c}\text { Não } \\
\text { apresenta }\end{array}$ \\
\hline
\end{tabular}

* Elaboração: OS AUTORES

No quadro 2, abaixo, sintetizamos as informações encontradas relativas às duas categorias de conteúdo analisadas: concepcõoes de interdisciplinaridade e obstáculos à interdisciplinaridade. Os dados desse segundo quadro permitem a identificação da abrangência dos conceitos utilizados para a interdisciplinaridade pelos diferentes autores, além da verificação dos principais obstáculos para a pesquisa e/ou para a prática da interdisciplinaridade, abordados nos trabalhos investigados.

Quadro 2. Dados obtidos para cada categoria analisada

\begin{tabular}{|c|c|c|}
\hline $\mathbf{N}^{o}$ & Concepções de Interdisciplinaridade & Obstáculos à Interdisciplinaridade \\
\hline A1 & $\begin{array}{l}\text { 1. Integração e interação entre as diversas áreas do } \\
\text { conhecimento }\end{array}$ & 1. Ausência de projetos interdisciplinares \\
\hline A2 & $\begin{array}{l}\text { 1. Convivência entre investigadores de distintas } \\
\text { disciplinas }\end{array}$ & Não apresenta \\
\hline A3 & $\begin{array}{l}\text { 1. Integração e interação entre disciplinas; } \\
\text { 2. Articulação de várias unidades curriculares; } \\
\text { 3. Trabalho em equipe; } \\
\text { 4. Movimento de disposição para o novo; } \\
\text { 5. Estratégia para unificação do conhecimento. }\end{array}$ & $\begin{array}{l}\text { 1. Espíritos solitários } \\
\text { 2. Perigos ideológicos presentes na organização do próprio saber } \\
\text { 3. Não clareza na comunicação } \\
\text { 4. Diversidade de conceitos } \\
\text { 5. Ausência de metodologia } \\
\text { 6. Não entendimento do caráter dinâmico da } \\
\text { interdisciplinaridade } \\
\text { 7. Desarticulação argumentativa } \\
\text { 8. Fundamentação epistemológica integrativa } \\
\text { 9. Dureza curricular } \\
\text { 10. Burocracias institucionais } \\
\text { 11. Manutenção disciplinar } \\
\text { 12. Formação tradicional dos professores } \\
\text { 13. Estrutura gerencial tradicional } \\
\text { 14. Lógica hierarquizante dos processos de ensino-aprendizagem }\end{array}$ \\
\hline A4 & $\begin{array}{l}\text { 1. Integração das várias áreas do conhecimento } \\
\text { 2. Intercomunicação efetiva entre as disciplinas }\end{array}$ & 1. Currículo fragmentado \\
\hline A5 & 1. Articulação e diálogo entre diferentes disciplinas & $\begin{array}{l}\text { 1. Organização burocrática-institucional } \\
\text { 2. Lógica neoliberal do capitalismo }\end{array}$ \\
\hline A6 & $\begin{array}{l}\text { 1. Intensidade das trocas entre as especialidades e grau de } \\
\text { integração real das disciplinas }\end{array}$ & Não apresenta \\
\hline A7 & $\begin{array}{l}\text { 1. Interlocução entre faculdades, saberes e cultura dos } \\
\text { indivíduos }\end{array}$ & Não apresenta \\
\hline A8 & 1. Interação entre áreas e saberes & Não apresenta \\
\hline A9 & $\begin{array}{l}\text { 1. Integração entre disciplinas } \\
\text { 2. Articulação dos saberes de vários campos do } \\
\text { conhecimento }\end{array}$ & 1. Estabelecimento de vínculos entre conteúdos disciplinares \\
\hline A10 & Integração entre as disciplinas & $\begin{array}{l}\text { 1. Escasso intercâmbio com as ciências da educação e cognitivas } \\
\text { 2. Ausência de entrosamento entre os professores } \\
\text { 3. Resistência a abrir mão do poder de sua disciplina } \\
\text { 4. Falta de preparo pedagógico e de formação }\end{array}$ \\
\hline
\end{tabular}


Quadro 2. (Continuação)

\begin{tabular}{|c|c|c|}
\hline $\mathbf{N}^{o}$ & Concepções de Interdisciplinaridade & Obstáculos à Interdisciplinaridade \\
\hline A11 & $\begin{array}{l}\text { 1. Integração do conhecimento das diversas áreas dos } \\
\text { saberes }\end{array}$ & 1. Professor catedrático \\
\hline $\mathrm{A} 12$ & 1. Interação de diferentes campos científicos & Não apresenta \\
\hline A13 & $\begin{array}{l}\text { 1. Troca de saberes entre disciplinas } \\
\text { 2. Troca intensa de saberes profissionais especializados } \\
\text { em diversos campos } \\
\text { 3. Troca de conhecimentos entre integrantes de mesma } \\
\text { equipe }\end{array}$ & $\begin{array}{l}\text { 1. Falta de diálogo } \\
\text { 2. Formação docente }\end{array}$ \\
\hline A14 & $\begin{array}{l}\text { 1. Algo comum a duas ou mais disciplinas ou ramos do } \\
\text { conhecimento } \\
\text { 2. Trabalho conjunto e interligado de campos } \\
\text { disciplinares }\end{array}$ & $\begin{array}{l}\text { 1. Institucional } \\
\text { 2. Métodos de avaliação dos projetos interdisciplinares } \\
\text { 3. Colaboração entre disciplinas }\end{array}$ \\
\hline A15 & $\begin{array}{l}\text { 1. Aproximação e convergência entre pontos de vistas do } \\
\text { sujeito e do objeto de investigação } \\
\text { 2. Axiomática comum a um grupo de disciplinas conexas } \\
\text { e as consequentes relações entre elas }\end{array}$ & Não apresenta \\
\hline A16 & 1. Colaboração e interação entre disciplinas e saberes & Não apresenta \\
\hline A17 & 1. Conexões entre os conceitos & Não apresenta \\
\hline A18 & 1. Interação entre saberes disciplinares & Não apresenta \\
\hline A19 & 1. Trabalho conjunto das disciplinas & Não apresenta \\
\hline A20 & 1. Interação de saberes disciplinares & Não apresenta \\
\hline A21 & 1. Caráter integrador, facilitador e motivador no ensino & Não apresenta \\
\hline A22 & 1. Relação entre diferentes disciplinas & Não apresenta \\
\hline A23 & $\begin{array}{l}\text { 1. Integração de saberes } \\
\text { 2. A relação entre a maneira de se entender a natureza } \\
\text { das ciências e suas implicações para o ensino } \\
\text { 3. Articulação de conhecimentos entre disciplinas }\end{array}$ & 1. Formação disciplinar dos professores \\
\hline A24 & 1. Articulação de saberes entre disciplinas & Não apresenta \\
\hline A25 & $\begin{array}{l}\text { 1. Relação de reciprocidade, de mutualidade, de } \\
\text { substituição da concepção fragmentária por uma } \\
\text { concepção unitária do ser humano } \\
\text { 2. Articulação de novos paradigmas curriculares na } \\
\text { comunicação do processo de percepção das várias } \\
\text { disciplinas } \\
\text { 3. Relação entre disciplinas e conteúdos } \\
\text { 4. Junção de áreas } \\
\text { 5. Axiomática comum a um grupo de disciplinas conexas } \\
\text { 6. Integração e convergência de ramos dos saberes }\end{array}$ & $\begin{array}{l}\text { 1. Formação docente } \\
\text { 2. Disputa de poder entre áreas }\end{array}$ \\
\hline A26 & $\begin{array}{l}\text { 1. Articulação dos diferentes saberes } \\
\text { 2. Intensas trocas entre os especialistas e grau de } \\
\text { integração entre disciplinas no interior de um mesmo } \\
\text { projeto } \\
\text { 3. Possibilidade do trabalho conjunto que respeita as } \\
\text { bases disciplinares específicas }\end{array}$ & Não apresenta \\
\hline A27 & 1. Intercâmbio entre aprendizagens & Não apresenta \\
\hline A28 & $\begin{array}{l}\text { 1. Diálogo entre disciplinas } \\
\text { 2. Modo de ação e de vivência } \\
\text { 3. Articulação entre disciplinas e áreas do conhecimento } \\
\text { 4. Dependência entre disciplinas } \\
\text { 5. Projeto comum e cooperação entre disciplinas }\end{array}$ & $\begin{array}{l}\text { 1. Formação disciplinar } \\
\text { 2. Falta de tempo para formação continuada } \\
\text { 3. Falta de confiança } \\
\text { 4. Rotatividade do corpo docente } \\
\text { 5. Falta de apoio metodológico na escola } \\
\text { 6. Postura dos alunos frente a novas metodologias } \\
\text { 7. Metodológicos } \\
\text { 8. Epistemológicos }\end{array}$ \\
\hline A29 & $\begin{array}{l}\text { 1. Uso de várias disciplinas para entender uma área ou } \\
\text { um problema }\end{array}$ & Não apresenta \\
\hline
\end{tabular}

* Elaboração: OS AUTORES

\section{DISCUSSÃO}

Com base nos dados contidos no quadro 2, foi possível colocar em discussão os elementos pertencentes a cada uma das duas categorias de análise, definidas a priori.

\section{Concepções de interdisciplinaridade}

O conceito de interdisciplinaridade aparece, explicitamente, em 16 trabalhos (A1, A3, A4, A5, A6, A9, A10, A12, A13, A14, A15, A16, A17, A25, A26 e A28) e, de forma implícita, em 13 (A2, A7, A8, A11, A18, A19, A20, A21, A22, A23, A24, A27 e A29). Nesse último caso, os 
autores a conceberam como: (a) interação de saberes de diferentes áreas do conhecimento (9 artigos: A8, A11, A18, A19, A20, A22, A23, A24 e A29); (b) convivência e intercâmbio de aprendizagens de distintos sujeitos (3 artigos: A2, A7 e A27); e (c) possuindo um caráter integrador, facilitador e motivador do ensino, com foco na prática docente (A21). Essas informações implícitas conferiram os mesmos significados à interdisciplinaridade, apresentados de forma explícita nos outros artigos.

Os conceitos de interdisciplinaridade encontram-se, portanto, nos 29 artigos analisados, todos eles embasados nos principais teóricos que se propõem ao estudo epistemológico desse instigante tema, abrangendo desde as primeiras discussões do campo científico - sobre o que vem a ser a interdisciplinaridade - até as definições mais complexas, formuladas na atualidade, além de documentos oficiais do Ministério da Educação Brasileiro e de Instituições de Ensino Superior da América Latina. Os autores que tiveram maior número de citações foram: Hilton Japiassu (A3, A6, A13, A25, A26 e A28), Ivani Fazenda (A3, A8 e A28) e Olga Pombo (A10 e A15). Observa-se que Japiassu é o teórico mais citado nos 29 trabalhos. Esse dado revela a importância desse autor para o estudo da interdisciplinaridade, visto que ele foi um dos responsáveis pela introdução da temática no meio acadêmico e científico brasileiro, na década de 1970, considerado como um dos precursores da literatura sobre o tema. Fazenda aparece em 3 trabalhos, com destaque no que diz respeito ao enfoque pedagógico e, principalmente, nas concepções que valorizam os aspectos da subjetividade e atitudes do sujeito como essenciais à realização da prática interdisciplinar. Pombo, por sua vez, é citada em 2 trabalhos, nos quais fica evidente a importância da sua presença nas discussões referentes: 1- ao modo recíproco de determinada transferência de conceitos, métodos e resultados de uma área disciplinar para outra; 2- à aproximação entre o sujeito e o objeto de investigação; 3- à complexidade desse conceito.

A partir dos elementos conceituais encontrados nos trabalhos pesquisados, trazemos à tona a discussão sobre a ideia da existência de diversos conceitos e formas de se conceber a interdisciplinaridade. As principais ideias encontradas nos artigos desta revisão integrativa são as seguintes: (a): "Axiomática comum a um grupo de disciplinas conexas [...]” (JAPIASSU, 1976, p. 74); (b): “[...] relação de reciprocidade, de interação que pode propiciar o diálogo entre os diferentes conteúdos desde que haja uma intersubjetividade presente nos sujeitos [...] e intensidade da troca entre os especialistas num mesmo projeto de pesquisa" (FAZENDA, 2006, p. 48), com foco na atitude do ser, enquanto pesquisador.

Outras concepções de interdisciplinaridade também se apresentam a partir dessa literatura, tais como: (c): "[...] uma nova forma de produção do conhecimento voltada aos fenômenos complexos [...] criando novas linguagens e instrumentos, além do compromisso de (re) ligar conhecimentos gerados pelo pensamento disciplinar." (PHILIPPI \& FERNANDES, 2015, p. 63); (d): “[...] qualquer forma de combinação entre duas ou mais disciplinas objetivandose a compreensão de um objeto a partir da confluência de pontos de vista diferentes cujo objetivo final seria a elaboração de síntese relativa ao objeto comum [...]." (GATTÁS \& FUREGATO, 2006, p. 325); (e): saberes nos quais “[...] as disciplinas são colocadas em relação, com o objetivo de proporcionar olhares distintos sobre o mesmo problema, visando a criar soluções que 
integrem teoria e prática, de modo a romper com a fragmentação do conhecimento." (BRASIL, 2012, p. 51) e; (f):

[...] convergência de duas ou mais áreas do conhecimento, não pertencentes à mesma classe, que contribua para o avanço das fronteiras da ciência e tecnologia, transfira métodos de uma área para outra, gerando novos conhecimentos ou disciplinas e faça surgir um novo profissional com um perfil distinto dos existentes, com formação básica sólida e integradora (BRASIL, 2010, p. 135).

Já para Morin (2003), a interdisciplinaridade pode significar uma ação de troca e cooperação, como também uma simples reunião de áreas que se posicionam a partir de seus domínios e estudos individualizados. Fazenda (1993), entretanto, nos chama a atenção para o fato de que a interdisciplinaridade, diferente da pluri e da multidisciplinaridade, configura-se como uma relação de reciprocidade, de mutualidade, de interação e diálogo - aspectos que dependem primeiramente da intersubjetividade dos sujeitos. A interdisciplinaridade é uma possibilidade de reflexões sobre o saber, assim como a oportunidade de criticá-lo, modificá-lo e ampliá-lo. É um meio possível de "[...] conseguir melhor formação [...], incentivo à formação de pesquisadores e de pesquisas [...], educação permanente [...], superação da dicotomia ensino-pesquisa [...]" (FAZENDA, 1993, p. 32) etc. Tanto no cenário nacional quanto no internacional, a interdisciplinaridade é concebida como uma integração recíproca pela transferência de conceitos, métodos e resultados entre campos disciplinares (POMBO, 2005; LÉTOURNEAU, 2008; PHILIPPI \& FERNANDES, 2015).

Outros autores foram citados em apenas um único artigo. A figura 1, abaixo, apresenta 39 teóricos - nacionais e internacionais - ligados à interdisciplinaridade.

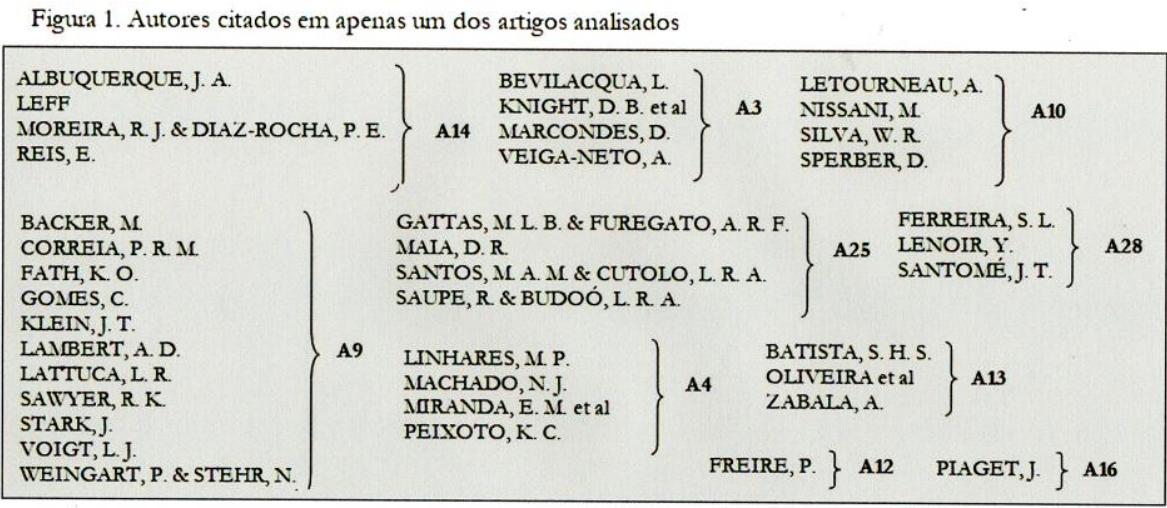

*Elaboracão: OS AUTORES

Observa-se que a maioria dos trabalhos analisados busca basear suas concepções e afirmações sobre o tema em mais de um teórico com ideias afins. Outro dado analisado é que em nenhum desses trabalhos foi apresentado um confrontamento de concepções sobre a interdisciplinaridade, deixando evidente a necessidade desta elaboração, para que tenhamos a possibilidade de vislumbrar aspectos que as diferenciam e que as aproximam. Faremos isso a seguir, utilizando alguns dos conceitos apresentados, agrupando os autores que têm diálogos convergentes. 
As concepções apresentadas sobre a interdisciplinaridade mostraram-se baseadas em diferentes perspectivas, indo da mais simples integração entre disciplinas (14 artigos: A1, A5, A8, A9, A10, A11, A12, A14, A16, A17, A18, A20, A22 e A29) às condições mais elaboradas de profundas interações e interconexões entre os sujeitos (09 artigos: A3, A4, A6, A13, A15, A23, A26, A27 e A28); da necessidade do trabalho em equipe (05 artigos: A2, A3, A13, A14 e A19) à restrita atitude de cada indivíduo que se faz interdisciplinar (02 artigos: A2 e A15); da visão mais simplificada que pensa a interdisciplinaridade a partir da existência de uma mínima justaposição das disciplinas (03 artigos: A21, A22 e A24) à mais complexa produção do saber (02 artigos: A25 e A28). Nota-se que as definições sobre a interdisciplinaridade apresentam múltiplos aspectos, que abrangem formas complexas de entendimento da nova estrutura hiperdinâmica do conhecimento, como observamos em alguns dos conceitos encontrados:

[...] método de pesquisa e de ensino suscetível de fazer com que duas ou mais disciplinas interajam entre si, esta interação podendo ir da simples comunicação das ideias até a integração mútua de conceitos, da epistemologia, da terminologia, da metodologia, dos procedimentos, dos dados e da organização da pesquisa [...] (JAPIASSÚ; MARCONDES apud XAVIER et al. 2017, p. 374, grifo nosso).

[...] estratégia de abordagem e tratamento do conhecimento em que duas ou mais disciplinas/unidades curriculares ofertadas simultaneamente estabelecem relações de análise e interpretação de conteúdos, com o fim de propiciar condições de apropriação, pelo discente, de um conhecimento mais abrangente e contextualizado (BRASIL apud VENTURA et al, 2014, p. 112, grifo nosso).

[...] processo metodológico de construção do conhecimento pelo sujeito com base em sua relação com o contexto, com a realidade, com sua cultura. Busca-se a expressão dessa interdisciplinaridade pela caracterização de dois movimentos dialéticos: a problematização da situação pela qual se desvela a realidade e a sistematização dos conhecimentos de forma integrada (FREIRE apud COSTA et al, 2017, p. 7, grifo nosso),

[...] processo de construção de conhecimentos teóricos e de práticas científicas que envolvem a compreensão de realidades complexas que, anteriormente fragmentadas, permitiram análises e sínteses disciplinares. A reconstrução interdisciplinar daquela complexidade envolve assim campos disciplinares em trabalho conjunto, interligados por um objetivo unificado (MOREIRA \& DIAZ-ROCHA apud CESCO et al, 2014, p. 11, grifo nosso).

[...] nova forma de pensar e fazer o ato de ensinar e aprender, pois por meio de uma postura interdisciplinar temos a oportunidade de ser aprendizes e produtores dos mais diversos saberes. [...] implica relação de reciprocidade, de mutualidade, de substituição da concepção fragmentária por uma concepção unitária do ser humano (GATTÁS \& FUREGATO apud SOUZA, 2016, p. 98, grifo nosso).

Ao analisarmos essas concepções, reaparece o caráter polissêmico e multifacetado da interdisciplinaridade. Partindo desses conceitos, notamos a presença de duas fortes características, a saber, (a): a que compreende a interdisciplinaridade a partir da existência de uma articulação e interação entre saberes e especialistas, não considerando o grau dessas interações; e (b): a que assimila a interdisciplinaridade a partir da intensidade do grau das interações entre sujeitos e campos disciplinares, não podendo existir interações mínimas ou fracas, mas, sim, interações fortes e profundas. Chamamos a atenção, aqui, para a ideia de "pequena" ou "grande" 
interdisciplinaridade, que é definida a partir do estabelecimento e do grau dessas conexões e interações (SOMMERMAN, 2012).

Observa-se que as definições possuem, como base, alguns fundamentos que têm revolucionado a produção acadêmica nos últimos anos, fazendo surgir novas reflexões pertinentes ao modo de se fazer pesquisa, assim como também novas maneiras de se praticar o ensino nas universidades. As principais ideias ou bases teóricas, filosóficas e reflexivas identificadas a partir desses nossos estudos foram as seguintes: atitude decolonial (MALDONADO-TORRES, 2016) (A29), as quatro dimensões do estilo pedagógico docente (CALLEJAS \& CORREDOR, 2002) (A22), as três categorias do conhecimento (SHULMAN, 1986) (A20), dialogicidade na educação (FREIRE, 1978) (A16), interacionismo sociodiscursivo (BRONCKART; MACHADO, 2009) (A21), modernidade como atitude (FOUCAULT, 1994) (A29), modernidade como projeto (HABERMAS, 1997) (A29), monocultura de mentes (SHIVA, 2003) (A11), multiletramentos (COPE; KALANTZIS, 2000) (A21), noção do desenvolvimento econômico (MALUF, 2000) (A14), os quatro pilares da educação e do conhecimento (DELORS, 1996) (A11 e A25), os seis saberes que compõem o reservatório que envolve o ensino (GAUTHIER ET AL, 1998) (A20), os sete saberes necessários à educação do futuro (MORIN, 2000) (A11 e A16), os cinco saberes do exercício da profissão docente (TARDIF, 2002) (A20), pensamento socioeconômico (PIAGET, 1976) (A17), revolução científica no interior da própria ciência (KUHN, 1989) (A14), teoria do pensamento complexo (MORIN, 2006) (A11 e A16), representação coletiva (BOURDIEU, 1982) (A17), teoria social da aprendizagem (WENGER, 1998, 2001) (A21 e A27) e, por fim, a visão sistêmica da vida (CAPRA, 1982) (A14).

A partir da análise dessas bases teóricas, observamos que os estudos utilizam múltiplos referenciais para fundamentar, principalmente, o caráter da interação entre diferentes áreas e saberes, proposta pela interdisciplinaridade. Contudo, percebe-se que os autores que utilizam bases teóricas relacionadas às questões do ensino e da aprendizagem (A21 e A27) consideram a interdisciplinaridade como sendo o intercâmbio entre as aprendizagens, com caráter integrador, facilitador e motivador do ensino. Essa perspectiva vai além da interação entre disciplinas e áreas do saber, contemplando, assim, de modo mais significativo, a ação dos sujeitos no processo de construção de uma determinada aprendizagem/conhecimento. Outra observação interessante é que os trabalhos A11, A14, A17, A20, A21, A22 e A29 fazem uso de mais de uma base teórica na sustentação de suas concepções sobre a interdisciplinaridade, nos levando à concluir que essas diferentes referências terminam por ocasionar as distintas concepções, levadas em consideração nesses artigos.

De modo geral, a interdisciplinaridade é apresentada como interações dialógicas que promovem múltiplas reflexões críticas ao conhecimento já produzido: "O diálogo, na equipe interdisciplinar, promove essa crítica, pois nenhum tema do conhecimento restringe-se a um campo delimitado de especialização [...]" (FAZENDA, 2006, p. 40-41) e, para que isto aconteça, é preciso que haja a abertura para o diálogo entre as diferentes disciplinas e entre as pessoas que constroem o conhecimento dentro dessas mesmas disciplinas (FAZENDA, 2006). A abertura, portanto, é necessária. É por essa perspectiva que se constrói o que se pode compreender como interdisciplinaridade. 
Segundo Fazenda (1993), a interdisciplinaridade não se ensina e não se aprende, mas é vivida e exercida pelos sujeitos, ou seja, a prática interdisciplinar é própria de cada indivíduo que é motivado a exercitar o cruzamento e a complementação dos saberes a partir de motivações e interesses que lhe são próprios. Todavia, uma questão se impõe: será que a interdisciplinaridade não pode mesmo ser ensinada e aprendida? Paulo Freire (1978) acredita que a existência do conhecimento demanda a existência dos sujeitos que, no processo interacional, ensinam e aprendem, aprendem e ensinam, caracterizando o que a Filosofia chama de gnoseologia - teoria do conhecimento -, considerando a não neutralidade do conhecimento mas, sim, o seu caráter dinâmico de transmissibilidade através das trocas e das experiências dos sujeitos. Portanto, toda forma de conhecimento pode ser ensinada e aprendida, experimentada pelos sujeitos. Logo, consideramos que a interdisciplinaridade, apesar de depender do caráter de motivação pessoal para a sua existência prática, pode ser experimentada, ensinada e aprendida de acordo com o interesse e a motivação de quem ensina e aprende e de quem aprende e ensina, sempre movido pelo desejo de aprender, isto é, pela abertura para o novo, para o interdisciplinar.

Como forma de melhor visualizar, resumidamente, a base conceitual da interdisciplinaridade, elaboramos, na Figura 2, abaixo, as especificidades tanto da disciplinaridade quanto da interdisciplinaridade.

Figura 2. Disciplinaridade e Interdisciplinaridade
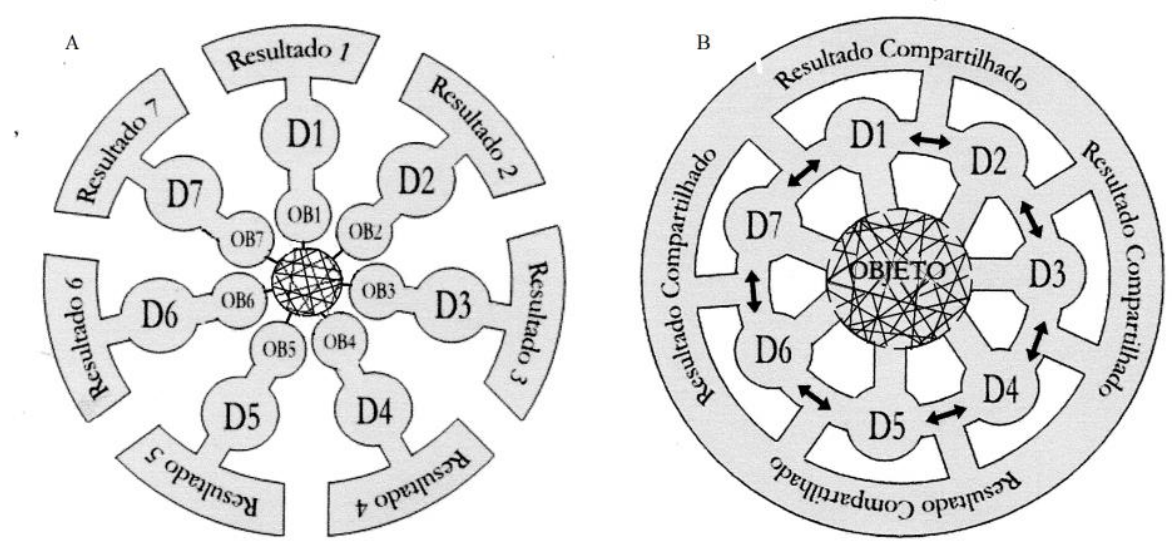

* Elaboração: OS AUTORES ( $(\mathrm{D}=$ Disciplina; $\mathrm{OB}=$ Objeto)

A Figura 2, em sua primeira estrutura, representa a disciplinaridade, cujos campos dos saberes extraem do complexo, interligado e dinâmico universo, os objetos de investigação, adotando-os como próprios e específicos de suas áreas, gerando, assim, resultados e conhecimentos pautados pela visão unilateral e que lhe são convenientes discutir. Já a segunda estrutura representa o núcleo comum das concepções sobre a interdisciplinaridade, encontrado nesta revisão integrativa, onde os campos disciplinares produzem discussões e elaboram conhecimentos a partir de um objeto central, de uma mesma problemática ou investigação complexa, através das trocas de informações e métodos das diversas áreas envolvidas. Consequentemente, o produto final é o resultado compartilhado, isto é, o conhecimento produzido com base na multidimensionalidade de olhares, concepções e saberes. 
A partir da revisão integrativa ora proposta, foi possível perceber a evolução do conceito de interdisciplinaridade através das atitudes dos sujeitos enquanto agentes que realizam, na prática, a pesquisa e o ensino, estando estes responsabilizados em adquirir competências e habilidades interdisciplinares para lidar com as demandas contemporâneas e com o enfrentamento dos diversos obstáculos que emergem, corriqueiramente, em todos os espaços do saber.

\section{Obstáculos à interdisciplinaridade}

Dos 29 artigos analisados, 17 não mencionam nenhum tipo de obstáculo ao ensino, à pesquisa e à prática interdisciplinar (A2, A6, A7, A8, A12, A15, A16, A17, A18, A19, A20, A21, A22, A24, A26, A27 e A29); 8 apresentam de um a três entraves, sem propor discussão (A1, A4, A9, A11, A13, A14, A23 e A25); e 3 trabalhos oferecem melhor atenção a esse aspecto (A3, A10 e A28), anunciando-os em todo o corpo do texto. Contudo, a discussão trazida à tona sobre os obstáculos se mostra superficial, ou seja, não apresenta uma ampla reflexão necessária acerca dos aspectos que se apresentam como relevantes ao entendimento da existência e do enfrentamento de tais barreiras.

Para melhor apresentar os dados e as discussões, os obstáculos foram organizados em três grupos: Institucionais, Epistemológicos e Relacionados ao Sujeito. Elaboramos a figura seguinte para melhor visualizarmos e analisarmos os resultados.

Figura 3. Obstáculos à Interdisciplinaridade

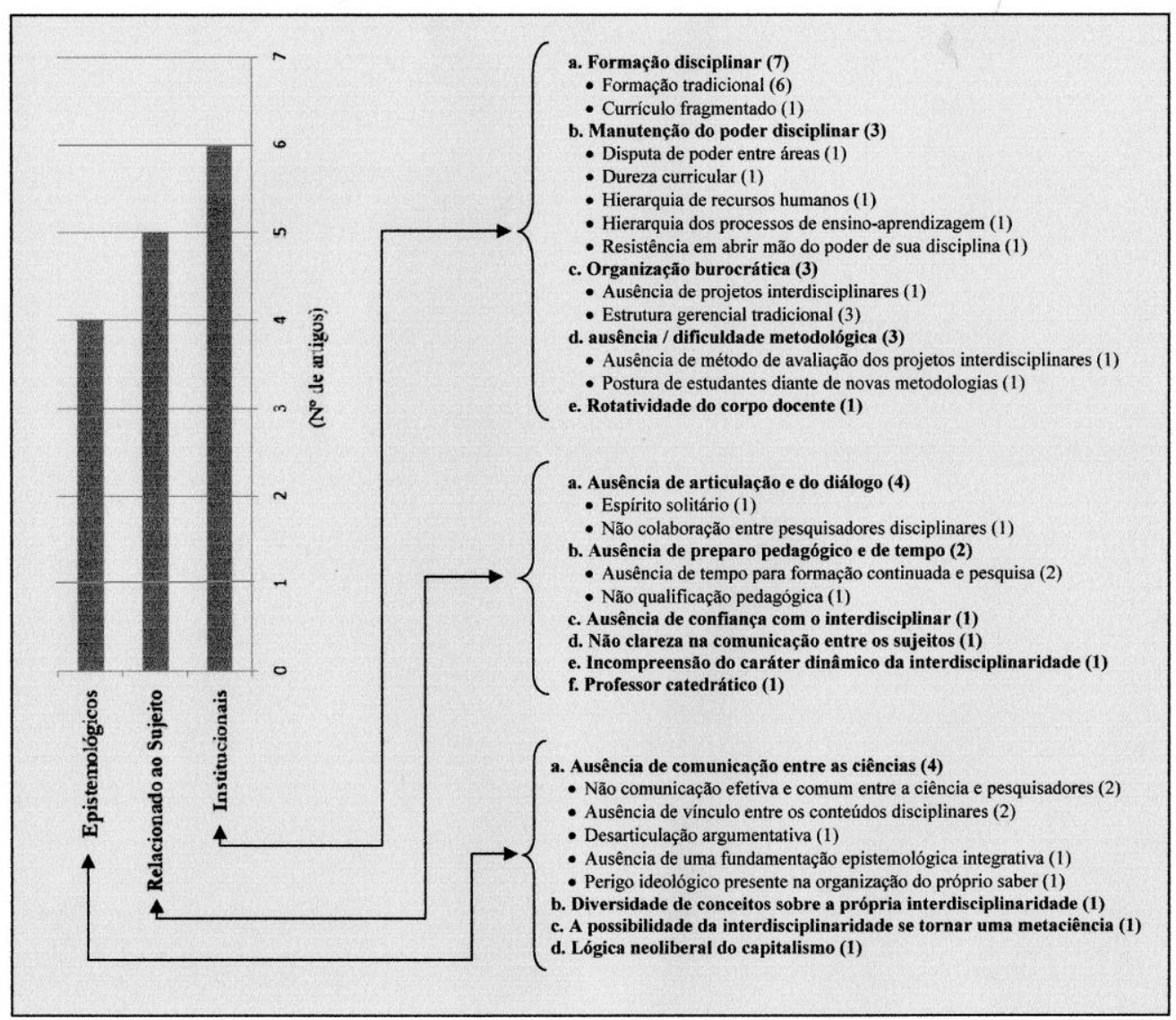

* Elaboração: OS AUTORES 
Pela observação da Figura 3, notamos que existe uma preocupação entre os pesquisadores em discutir ou, no mínimo, apresentar quais são os obstáculos que têm dificultado a ampliação e o melhor desenvolvimento do ato ou atitude interdisciplinar. Discutiremos, portanto, tais obstáculos de acordo com cada subcategoria.

\section{Obstáculos Institucionais}

A interdisciplinaridade, do ponto de vista científico e acadêmico, acontece, em sua maior parte, nas universidades federais e estaduais distribuídas pelo Brasil. São nessas instituições que encontramos as experiências interdisciplinares mais exitosas. Entretanto, é também nelas que aparecem os obstáculos a tal prática, seja pelos regulamentos que normatizam suas atividades, seja pelas hierarquias que as constituem. Para uma melhor discussão, apresentaremos os obstáculos que compreendem esta subcategoria e que mais aparecem nos artigos:

a) Formação disciplinar: aparece, explicitamente, em 07 trabalhos (A3, A4, A10, A13, A23, A25 e A28) e se refere ao modelo de formação tradicional, ofertado aos professores e pesquisadores (A3, A10, A13, A23, A25 e A28), e ao currículo fragmentado (A4). A formação disciplinar cumpre um papel significativo para solucionar questões simples ou que não exijam complexidade de investigações, mas deixa a desejar diante dos problemas complexos que circundam quase todos os aspectos da vida, nos dias atuais. $\mathrm{O}$ fomento à formação disciplinar não corresponde eficazmente à busca de soluções para problemas complexos e universais, principalmente diante de uma origem cultural ampliada, das ideias e concepções que envolvem os sujeitos e dos paradigmas conceituais e estruturantes que emergem entre as fronteiras dos campos dos saberes. Segundo Raynaut (2011), os sistemas de formação de pesquisa disciplinar especializados produzem cientistas com mínima capacidade de reflexão e de crítica, sendo necessária a ampliação intelectual desses indivíduos, o que pode ser desenvolvido pelas condições inovadoras que ultrapassam as barreiras disciplinares. A formação disciplinar que se estabelece diante do currículo fragmentado tende a dificultar a prática da interdisciplinaridade, porém esta ideia não corresponde a uma regra, visto que diversos docentes e pesquisadores têm tido atitudes interdisciplinares em suas buscas pelo conhecimento, em virtude da compreensão da dinâmica que hoje está se estabelecendo em todas as modalidades de ensino e de pesquisa.

b) Manutenção do poder disciplinar: aparece, explicitamente, em 03 trabalhos (A3, A10 e A25). É identificada como dureza e manutenção curricular (A3), resistência que professores e pesquisadores têm em abrir mão do poder de sua disciplina (A10), disputa de poder entre áreas (A25) e hierarquia de recursos humanos (A13). A análise sobre os argumentos relacionados a esse obstáculo evidencia o interesse que as disciplinas e seus envolvidos têm em manter o monopólio disciplinar, aspecto que configura a estrutura da maioria das universidades do país. Pela manutenção do poder disciplinar, os indivíduos buscam assegurar autonomia e independência na forma de produção dos saberes sobre os objetos de investigação que lhes são próprios, sem sofrer interferência para além de suas fronteiras, mantendo a rigidez hierarquicamente resistente que se estabelece na disciplinaridade, gerando hierarquias nos diversos aspectos do processo de ensino-aprendizagem e de recursos humanos (A3). Essa concepção é fortemente demarcada nas ciências chamadas "duras" que, historicamente, estabeleceram monopólios e fecharam-se nas 
fronteiras conceituais e metodológicas que lhes conferem prestígio, poder e controle no campo científico. Críticas a essa configuração disciplinar evidenciam que esse poder controlador sobre os indivíduos não se opera simplesmente pela consciência, pela ideologia ou pela criação de epistemes categorizadas, mas, sobretudo, organiza o controle dos corpos numa sociedade disciplinada (FOUCAULT, 2012). Esse obstáculo é visivelmente observável nas instituições de ensino superior no Brasil, fato que se comprova pelas ações que vão de encontro aos novos e crescentes modelos de formação, baseados no regime de ciclos implantado em algumas universidades públicas do país. A rigor, a interdisciplinaridade admite e prioriza a autonomia das disciplinas e considera importante o crescimento disciplinar para responder às questões específicas e menos complexas, mas sem perder de vista a necessidade de interações. Fazenda (2003, p. 26) afirma que "[...] uma atitude interdisciplinar respeita a autonomia de voo de cada um, pois acredita que o estabelecimento da marca do pesquisador, que o torna único e lhe confere autonomia, está na forma como estabelece parceria.".

c) Organiżação burocrática e institucional: aparece, explicitamente, em 03 trabalhos (A3, A5 e A14), como estrutura gerencial tradicional e burocracias institucionais (A3, A5 e A14), como forças que limitam a ação interdisciplinar pelos discursos oficiais, pelas ações normativas e pelas regulamentações internas presentes no contexto das universidades. Compreendemos que a atual organização das universidades ainda limita a prática interdisciplinar, pois sua estrutura de organização administrativa, financeira e pedagógica alimenta quase todos os demais obstáculos que aparecem na Figura 3. De acordo com CESCO et al (2014, p. 57), "[...] o desafio da interdisciplinaridade passa, inicialmente, pela questão institucional e estende-se à forma e aos métodos de avaliação dos trabalhos interdisciplinares". Esse obstáculo nos estimula a pensar na necessidade de novas formas de universidade nos dias atuais, desburocratizando as formas de produção dos saberes, permitindo, assim, maiores possibilidades de atuação "intercampos".

A estrutura da organização institucional, notadamente, é outro grande desafio para a interdisciplinaridade, uma vez que muitas instituições estão estruturadas segundo modelos tradicionais de organização e funcionamento, com currículos engessados, fixos, disciplinares, verticais e que não correspondem às demandas da formação holística que, segundo Rocha (2010), é uma educação integral, que visa à formação do indivíduo como um todo, explorando suas inteligências e potencialidades. Esse fato é evidenciado em muitas universidades que ou não dialogam ou pouco dialogam com as graduações conhecidas como 'Bacharelados Interdisciplinares ${ }^{5}$. As universidades precisam de fortíssimas e urgentes transformações para que a interdisciplinaridade avance em seus espaços. Para tanto, é preciso a elaboração de projetos interdisciplinares em todos os níveis da educação, sobretudo no ensino superior. A falta de tais projetos aparece, portanto, como outro obstáculo à interdisciplinaridade (A1).

d) Ausência / dificuldade metodológica: aparece, explicitamente, em 03 trabalhos (A3, A14 e A28), como ausência de metodologia interdisciplinar (A3 e A28), ausência de método de avaliação para o projeto interdisciplinar (A14), falta de apoio metodológico aos professores e

\footnotetext{
${ }^{5}$ Bacharelados Interdisciplinares são graduações ofertadas a partir do modelo de formação por ciclos, nos quais os componentes curriculares fixos de base são ofertados através de uma perspectiva múltipla de diálogo entre os saberes, caracterizando as discussões teóricas e a produção de conhecimentos interdisciplinares. 
pesquisadores, postura de estudantes frente a novas metodologias (A28). Esse obstáculo é caracterizado como o não estabelecimento de um método para o trabalho interdisciplinar. Vale ressaltar que a interdisciplinaridade, por natureza, não busca uma metodologia única, mas, sim, envereda-se pelas metodologias existentes, ampliando-as, possibilitando, assim, um caráter interdisciplinar para as pesquisas. A crítica está nos procedimentos pelos quais as pesquisas se fazem valer; estão fundamentadas nos padrões rigorosos do positivismo e do método cartesiano, já não mais eficazes para responder às questões que surgem na contemporaneidade, mas que ainda se mantêm nas universidades no Brasil. Outro fato é o seguinte: também no ambiente da sala de aula, os professores sentem dificuldades em propor o ensino interdisciplinar, em virtude de muitas objeções metodológicas, principalmente pela manutenção da enraizada metodologia tradicionalista que se faz fortemente presente nos currículos, na organização e no fazer pedagógico, mantido pelas universidades.

Outro obstáculo institucional é a rotatividade do corpo docente numa mesma pesquisa ou instituição (A28), aspecto que pode ser considerado como uma barreira para a efetivação do desenvolvimento das práticas interdisciplinares, uma vez que pessoas que já atuam de modo interdisciplinar podem ser substituídas por outras que podem não conhecer, não concordar ou não se sentir motivadas em atuar pelos caminhos da interdisciplinaridade. Nessa situação, há perda significativa do trabalho que já havia sido desenvolvido, sobretudo nos cursos de graduação e pós-graduação de base interdisciplinar. Essa realidade pode ser observada do ponto de vista administrativo, pedagógico, financeiro etc. Outro obstáculo - a ausência de projetos interdisciplinares (A1) - confirmou a tendência das universidades latino-americanas de se pautarem sobre modelos disciplinares de ensino e produção de saberes, tanto na graduação quanto na pósgraduação.

Os obstáculos institucionais são de extrema importância para serem pensados, porque a ideologia, a organização e a estrutura da instituição podem ou não favorecer a prática interdisciplinar, o que pode, evidentemente, alavancar ou atrasar o desenvolvimento de pesquisas que, notadamente, demandam uma instituição aberta e flexível à interdisciplinaridade.

\section{Obstáculos Relacionados ao Sujeito}

A interdisciplinaridade, vista como uma prática entre os sujeitos, confere um caráter único a esse paradigma de produção de conhecimento, pois não se baseia apenas em modelos teóricos, conceituais e procedimentais, mas permite que cada indivíduo explore, dentro de suas possibilidades cognitivas, diversas fontes que sejam possíveis de serem utilizadas na produção do saber. Compreendendo a interdisciplinaridade mais como uma atitude do que como uma teoria ou metodologia, alguns estudos apontam obstáculos inerentes aos indivíduos, que podem vir a dificultar o ato interdisciplinar. São eles:

a) Ausência de articulação e do diálogo: aparece, explicitamente, em 04 trabalhos (A3, A10, A13 e A14), caracterizada pela falta de entrosamento e de diálogo entre professores e pesquisadores (A10 e A13), pela não colaboração entre pesquisadores disciplinares (A14) e pela existência de espíritos solitários, de atitude individualista e não humilde, presente nos pesquisadores disciplinares (A3). Pautando a análise desse obstáculo à luz dos estudos de Fazenda 
(2006), consideramos que a articulação e o diálogo, seja numa pesquisa ou numa equipe de trabalho interdisciplinar, têm como base a subjetividade dos sujeitos. Isso reafirma o reconhecimento de que a interdisciplinaridade é, também, uma prática individual, pautada no desenvolvimento de atitudes favoráveis ao seu exercício. Sendo os sujeitos dotados de desejos próprios e com inserções nas mais diversas áreas que tangem a vida, é preciso deixar claro que o desejo individual, mesmo que seja contrário à prática da interdisciplinaridade, deve ser respeitado. Essa é outra marca da interdisciplinaridade, que reconhece os sujeitos em suas subjetividades, respeitando as mais diversas formas de atos de produção de conhecimentos, mesmo quando sustenta e defende a ideia da prática, pautada em princípios interdisciplinares.

b) Ausência de preparo pedagógico e de tempo: aparece, explicitamente, em 02 trabalhos (A10 e A28), sendo descrito como a falta de qualificação pedagógica e de formação para lidar com questões interdisciplinares (A10) e a falta de tempo para a formação continuada e para a pesquisa (A28). Esses obstáculos nos levam a concordar quanto ao seguinte: "[...] é um desafio para o professor romper com os limites da sua própria formação fragmentada e construir relações com outras áreas do conhecimento [...]" (ROSSONI \& LAMPERT apud SOUSA \& BASTOS, 2016, p. 107). Sendo os sujeitos capazes de transformações cognitivas, é possível que, independentemente de qualquer obstáculo, os indivíduos consigam caminhar pela via interdisciplinar, na medida em que essa prática torna viável o desenvolvimento de suas investigações. Em outras palavras, independentemente de sua formação disciplinar, os docentes e pesquisadores podem desenvolver competências e habilidades úteis à prática interdisciplinar. Isso demonstra a presença de virtudes epistemológicas, abertura para o novo, para o diálogo, além da humildade em compreender que os saberes, quanto mais ampliados e multifacetados, melhor corresponderão a determinadas realidades do mundo complexo: "La práctica docente, depende pues, de su postura ante simismo y ante el mundo, y de los procesos simbólicos que utilice para expresarse" (RESTREPO \& CAMPO apud GÓMEZ GÓMEZ et al., 2015, p. 221). Fazenda (2006) também afirma que a ação interdisciplinar só existe quando é mediada pelo interesse e pelo diálogo, o que está para além do modo como os indivíduos foram formados. Logo, vale à pena a atitude de compromisso com o saber, pelo qual determinados indivíduos apreendem e desenvolvem ideias a partir da compreensão e inconformismo com um limitado alcance, produzido pela monodisciplinaridade.

Outros obstáculos, que estão relacionados aos sujeitos, apareceram nos artigos da seguinte maneira: ausência de confiança com o interdisciplinar (A28); não clarę̧a na comunicação entre os sujeitos (A3); professor catedrático (A11); incompreensão do caráter dinâmico da interdisciplinaridade (A3). Tais obstáculos complementam os demais já descritos e fortalecem a discussão segundo a qual a atitude dos sujeitos é o ponto chave para que a interdisciplinaridade avance ou retroceda.

\section{Obstáculos Epistemológicos}

Compreender as bases epistemológicas da interdisciplinaridade é essencial para o desenvolvimento e a concretização de sua prática, pois permite a evolução do entendimento do "que" (objeto), do "como" (método) e do "porquê" (finalidade) da interdisciplinaridade. Na medida em que a interdisciplinaridade é melhor compreendida, mais fácil e eficaz é a sua aplicabilidade e contextualização, seja na pesquisa, no ensino, na extensão ou em projetos que 
alcancem todas as modalidades do ensino superior no Brasil. Contrário à isso são os obstáculos que surgem diante dessa complexidade epistemológica, destacados nos trabalhos analisados, quais sejam:

a) Ausência de comunicação entre as ciências: aparece, explicitamente, em quatro artigos (A3, A9, A10 e A14), caracterizada como a não comunicação efetiva e comum entre as ciências e seus pesquisadores (A3, A10), o não estabelecimento de vínculo entre os conteúdos disciplinares (A9 e A14), a desarticulação argumentativa, a ausência de uma fundamentação epistemológica integrativa e o perigo ideológico presente na organização do próprio saber (A3). Nota-se que esses obstáculos geram uma diversidade de conflitos entre as ciências que percorrem caminhos tradicionais nas formas de produção do conhecimento e as ciências que buscam uma abordagem mais ampla, na busca de soluções para os mais complexos problemas na contemporaneidade. A comunicação entre as ciências, sejam elas "duras" ou "leves", é umas das chaves que abrirá portas de acesso para a interdisciplinaridade. Para tanto, um caminho a seguir é a busca do estabelecimento de relações entre saberes, pois o diálogo e a integração entre eles são essenciais para a prática de interação entre as ciências, o que nos leva a pensar numa reestruturação de currículos, programas e áreas de conhecimento.

b) Diversidade de conceitos sobre a própria interdisciplinaridade: aparece, explicitamente, em apenas um artigo (A3). Já afirmamos que a interdisciplinaridade é múltipla e dinâmica no que se refere à prática. Isso se deve e reflete a polissemia de concepções que abriga esse paradigma. $\mathrm{O}$ fato da interdisciplinaridade não possuir um modelo único de atuação e operacionalização lhe é conferido pela possibilidade de tráfego entre as mais diversas teorias e ideias, o que a torna vulnerável às críticas por aqueles que preferem o fazer já cientificamente firmado, que é o disciplinar, ao invés de navegar pelas rotas da interdisciplinaridade, que busca seu lugar na ciência não como mais uma área de saber, mas, sim, como outras possibilidades de se escavar e se correlacionar conhecimentos novos e já existentes. Talvez esse seja o grande desafio da interdisciplinaridade, visto ser esse aspecto o que mais sustenta as críticas feitas pelos docentes considerados disciplinares.

$\mathrm{Na}$ atualidade, há uma concordância de que a base epistemológica da interdisciplinaridade caminha para uma definição mais convergente, existindo menor discordância quanto ao que ela é. Outro fato é que a ciência a reconhece como uma prática emergente de incontestável valor, ainda que polêmica, pois abriga uma dinâmica mais flexível na investigação e produção do conhecimento. Existe uma concordância de entendimento entre os cientistas de que a realidade é pluridimensional e, nesse sentido, suscetível de ser abordada de diferentes maneiras.

Consideramos que a busca por uma tentativa de conferir um conteúdo concreto à interdisciplinaridade pode levar à perda da diversidade que tal prática científica e pedagógica propõe no ambiente acadêmico e científico. Em outras palavras, não podemos falar de uma interdisciplinaridade específica, mas, sim, da possibilidade de várias interdisciplinaridades, sem esvaziar os debates e os confrontos teóricos. Conforme Philippi Jr \& Fernandes (2015), existem várias formas de se teorizar e de se praticar a interdisciplinaridade, em virtude dos complexos e dinâmicos problemas que as sociedades contemporâneas enfrentam. 
Outros obstáculos epistemológicos aparecem nos artigos ora pesquisados, tais como: possibilidade da interdisciplinaridade se tornar uma metaciência (A3) e lógica neoliberal do capitalismo (A5). No geral, o obstáculo epistemológico é bastante enfatizado na literatura interdisciplinar (JAPIASSU, 1976; FAZENDA, 2006; KLEIN, 1990), o que nos faz perceber a importância dada à busca de soluções que possam minimizar a dificuldade de comunicação entre os sujeitos, para que os mesmos possam melhor compreender a linguagem de cada área disciplinar e estabelecer uma comunicação comum para o desenvolvimento do trabalho.

Esses diversos obstáculos são amplamente questionados e discutidos entre teóricos, pesquisadores e professores que atuam com a interdisciplinaridade. Nos dias atuais, as práticas que se opõem ao saber interdisciplinar estão em pauta nas discussões, pois é consenso o entendimento de que a interdisciplinaridade é necessária para responder às perguntas complexas, para resolver determinados tipos de problema e para adquirir uma compreensão de certos temas, proporcionando novas reflexões e inovações nos saberes.

\section{CONSIDERAÇÕES FINAIS}

As discussões sobre a interdisciplinaridade crescem cada vez mais nos ambientes de produção do saber, isto é fato! Diante dessa realidade, a compreensão de seus conceitos, objetos e resultados são indubitavelmente relevantes, haja vista que possibilitam maior amplitude de seu alcance, de modo a atender às demandas das novas, dinâmicas e complexas visões sistêmicas que rompem com o paradigma da simplificação e da especialização.

Nota-se que as discussões sobre a interdisciplinaridade continuam em alta no campo científico e acadêmico, sendo essa a área que mais cresce no Brasil - no ensino, na pesquisa e na extensão. Tais discussões abrangem conceitos polissêmicos, multifacetados, que compreendem complexos modos de entendimento da nova estrutura hiperdinâmica do conhecimento, sendo, assim, concebida por diversos modos: teóricos/práticos, inclusivos/agregativos, sistêmico/sujeito e genérico/específico, fazendo com que se firme ainda mais como um paradigma de produção do conhecimento que tem por característica principal a ênfase no pluralismo prático, destacando, assim, a sua natureza dinâmica e flexível.

As múltiplas concepções sobre a interdisciplinaridade convergem, entretanto, para a ideia de integralidade, seja ela dos saberes, das aprendizagens, dos sujeitos ou das áreas disciplinares. Isso significa afirmar que, mesmo apresentando diferentes perspectivas e enfoques, os conceitos sobre a interdisciplinaridade têm como base referencial a ideia da complexidade, da necessidade da visão multifacetada da realidade, dos fenômenos, dos problemas, do ser humano e da vida como um todo. O que se mostra fundamental é que se busque ampliar as articulações ou integrar as diferentes áreas dos saberes em torno de um objeto de estudo, em seus aspectos teóricos e metodológicos. Esse, com certeza, pode ser considerado um dos maiores desafios para a interdisciplinaridade nos dias atuais.

Sendo a interdisciplinaridade sustentada pela complexidade (MORIN, 2006), ela não pode caminhar na direção do reducionismo de práticas e da produção de saberes. Esse também é outro desafio da interdisciplinaridade: estabelecer-se num campo científico, onde a grande maioria dos que fazem parte dele ainda caminha com uma consciência enraizada na 
disciplinaridade, seja pelo comodismo da praticidade de se encontrar procedimentos já prédeterminados para a pesquisa/ação ou pela falta de disposição para navegar por um oceano de complexidades, que exige dos que nele navegam a predisposição para o estabelecimento de links, os mais variados possíveis, para produzir conhecimentos mais próximos da realidade do mundo e dos seus mais diversos fenômenos.

Do nosso ponto de vista, uma das maiores contribuições oferecidas por este estudo encontra-se, justamente, nas reflexões sobre os obstáculos que dificultam a prática da interdisciplinaridade. A integração dos vários obstáculos possibilitou avançarmos nas discussões sobre os entraves à interdisciplinaridade que, sobretudo, emanam da manutenção do rígido estabelecimento da monodisciplinaridade, identificando alguns possíveis desafios para essa prática de produção do saber. Um destaque é dado ao obstáculo que se refere à formação disciplinar dos profissionais da educação, como um convite para pensar na necessidade e no desafio da formação continuada, na reformulação dos currículos e dos programas de ensino, pois é, como constatamos, no ambiente das salas de aula e das pesquisas que os docentes têm a oportunidade de desenvolver práticas interdisciplinares.

Enfim, faz-se necessário investir mais ainda no conhecimento sobre a interdisciplinaridade, seja pela atitude individual, coletiva, institucional ou governamental. Não podemos fechar os olhos diante da realidade que se mostra mais complexa a cada instante nem, sobretudo, manter nosso olhar fixado nos padrões disciplinares, uma vez que existem questões que necessitam de intersaberes, olhares complexos e interligados. Não podemos negar a disciplinaridade e nem abandoná-la, mas é preciso avançar no conhecimento e na compreensão de que a disciplinaridade e a interdisciplinaridade se complementam, mesmo caminhando em direções diferentes: a primeira, caminha em busca da resolução de problemas de natureza menos complexa, enquanto a segunda se debruça em resolver questões de natureza mais complexa. Portanto, uma não invalida a outra e, nesse caminhar, ambas se complementam e se auxiliam. Avançar é uma necessidade e também um desafio... A interdisciplinaridade configura-se, portanto, como um ambiente complexo, de múltiplas possibilidades de realizações, seja do ponto de vista teórico ou prático, do trabalho em equipe ou da atitude individual do sujeito diante da complexidade do pensamento, do ser humano, da natureza e do mundo contemporâneo.

\section{REFERÊNCIAS BIBLIOGRÁFICAS}

ACEVEDO RINCON, J. P.; FIORENTINI, D. Práticas na formação dos licenciados em matemáticas: a experiência de uma prática interdisciplinar. Rev. Fac. Cienc. Tecnol. [online], n. 40, p. 209-239, 2016. Disponível em: https://bit.ly/2SY9w7p. Acesso em: 10 mai. 2018.

ARAMAN, E. M. O.; BATISTA, I. L. O Processo de Construção de Abordagens Históricas na Formação Interdisciplinar do Professor de Matemática. Bolema [online], v. 31, n. 57, p. 380-407, 2017. Disponível em: https://bit.ly/2yYWFtk. Acesso em: 10 mai. 2018.

BARDIN, L. Análise de Conteúdo. 3. ed. Lisboa: Ed. 70, 2004. 226 p. 
BOURDIEU, P. Ce que parler veut dire. L'économie des échanges symboliques. Paris: Fayard, 1982.

BRASIL. Ministério da Educação. Instituto Nacional de Estudos e Pesquisas Educacionais Anísio Teixeira. Sistema Nacional de Avaliação da Educação Superior. Instrumento de avaliação de cursos de graduação presencial e a distância. Brasília, maio 2012. Disponível em: https://bit.ly/2z32ciu. Acesso em: 27 set. 2018.

Ministério da Educação. Coordenação de Aperfeiçoamento de Pessoal de Nível Superior. Plano Nacional de Pós-Graduação - PNPG 2011-2020. Brasília, 2010. Disponível em: https://bit.ly/2yYX6Uu. Acesso em: 27 set. 2018.

BRONCKART, J. P.; MACHADO, A. R. (Re-)configurações do trabalho do professor construídas nos e pelos textos: a perspectiva metodológica do grupo ALTER-LAEL. In: Cristóvão, V. L. P. e Tardelli-Abeu, L. S. (org.). Linguagem e educação: o trabalho do professor em uma nova perspectiva. Campinas: Mercado de Letras, 2009. p. 31-77.

CALLEJAS, R.; CORREDOR, M. La renovación de los estilos pedagógicos: colectivos para la investigación y la acción de la universidad. Revista Docencia Universitaria, UIS, v. 3, n. 1, p. 41-61, 2002. Disponível em: encurtador.com.br/fDQUZ. Acesso em: 10 mai. 2018.

CAPES. Documento De Área - Área 45: Interdisciplinar. Disponível em: https://www.capes.gov.br/images/Documento_de_\%C3\%A1rea_2019/INTERDISCIPLIN AR.pdf. Acesso em: 20 de ago. 2019.

CAPRA, F. O ponto de mutação: a ciência, a sociedade e a cultura emergente. São Paulo: Cultrix, 1982.

CARVALHO, E. A. Educação para o século XXI. In: ALMEIDA, Maria da Conceição de; KNOBBE, Margarida; ALMEIDA, Ângela Maria de. Polifônicas idéias: por uma ciência aberta. Porto Alegre: Sulina, 2003.

CASTIBLANCO, O.; NARDI, R. Interpretando la estructura curricular de programas brasileños de Licenciatura en Física, a partir de una perspectiva epistemológica de la Didáctica de la Física. Rev. electrón. investig. educ. cienc. [online], v. 9, n. 1, p. 54-69, 2014. Disponível em: https://bit.ly/2DavoqJ. Acesso em: 10 mai. 2018.

CESCO, S.; MOREIRA, R. J.; LIMA, E. F. N. Interdisciplinaridade, entre o conceito e a prática um estudo de caso. Rev. bras. Ci. Soc. [online], v. 29, n. 84, p. 57-71, 2014. Disponível em: https://bit.ly/2F9Fo6s. Acesso em: 10 mai. 2018.

COPE, B.; KALANTZIS, M. Multiliteracies: Literacy Learning and the Design of Social Futures. London: Routledge, 2000.

CORREIA, P. R. M.; CORDEIRO, G. B.; CICUTO, C. A. T.; JUNQUEIRA, P. G. Nova abordagem para identificar conexões disciplinares usando mapas conceituais: em busca da interdisciplinaridade no Ensino Superior. Ciênc. educ. (Bauru) [online], v. 20, n. 2, p. 467-479, 2014. Disponível em: https://bit.ly/2qCGMEj. Acesso em: 10 mai. 2018. 
COSTA, C. A.; LOUREIRO, C. F. A interdisciplinaridade em Paulo Freire: aproximações político-pedagógicas para a educação ambiental crítica. Rev. Katálysis [online], v. 20, n. 1, p. 111-121, 2017. Disponível em: https://bit.ly/2FcCNZq. Acesso em: 10 mai. 2018.

DELORS, J. (org.). Educação: um tesouro a descobrir. Relatório para a UNESCO da Comissão Internacional sobre Educação para o século XXI. São Paulo: Cortez, 1996.

FAZENDA, I. A avaliação na pós-graduação sob a ótica da interdisciplinaridade. In: QUELUZ, A. G. (Org.). Interdisciplinaridade: formação de profissionais da educação. São Paulo: Pioneira Thomson Learning, 2003. p. 23-28.

. Interdisciplinaridade: qual o sentido? $2^{\mathrm{a}}$ ed. São Paulo: Paulus, 2006.

. Interdisciplinaridade: um projeto em parceria. São Paulo: Loyola, 1995.

1993.

Integração e interdisciplinaridade no ensino brasileiro. São Paulo: Edições Loyola,

FILHO, J. B.; MAINERI, M. M.; ARAUJO, R. S. L. Para além do pensamento domesticado: reflexões sobre docência e educação superior no contexto da saúde. Paradigma [online], v. 37, n. 2, p. 195-208, 2016. Disponível em: https://bit.ly/2SWkWso. Acesso em: 10 mai. 2018.

FOUCAULT, M. Microfísica do poder. Rio de Janeiro: Graal, 2012.

. ¿ Qué es la Ilustración? [Qu'est-ce que les Lumières?]. Actual, n. 28, p. 1-18, 1994. Disponível em: https://bit.ly/2FlijxJ. Acesso em 20 out. 2018.

FREIRE, P. Pedagogia do Oprimido. 5. ed. Rio de Janeiro: Paz e Terra, 1978.

GATTÁS, M. L. B.; FUREGATO, A. R. F. Interdisciplinaridade: uma contextualização. Rev. Acta Paul Enferm [online], v. 19, n. 3, p. 323-327, 2006. Disponível em: https://bit.ly/2z7dHFM. Acesso em: 20 out. 2018.

GAUTHIER, C. et al. Por uma Teoria da Pedagogia: pesquisas contemporâneas sobre o saber docente. 2. ed. Ijuí: UNIJUÍ, 1998.

GÓMEZ GÓMEZ, L.; BUSTAMANTE PARRA, A. C.; CASTIBLANCO MORALES, I. L. Estilos pedagógicos de docentes de la facultad de educación de la UPTC en los proyectos pedagógicos e investigativos I y II. Prax. Saber [online], v. 6, n. 12, p. 209-240, 2015. Disponível em: https://bit.ly/2RGVBkI. Acesso em: 10 mai. 2018.

HABERMAS, J. Modernity: an unfinished project. In: D’ENTRÈVES, Maurizio Passerin; BENHABIB, Seyla (Eds.). Habermas and the unfinished project of modernity: critical essays on the philosophical discourse of modernity. Cambridge: MIT Press, 1997. p. 38-58.

JAPIASSU, H. Interdisciplinaridade e patologia do saber. Rio de Janeiro: Imago, 1976.

JODELET, D. A representação: noção transversal, ferramenta da transdisciplinaridade. Cad. Pesqui. [online], v. 46, n. 162, p. 1258-1271, 2016. Disponível em: https://bit.ly/2DawjaF. Acesso em: 10 mai. 2018. 
JOSE, W. D.; BRAGA, G. R.; NASCIMENTO, A. Q. B.; BASTOS, F. P. ENEM, temas estruturadores e conceitos unificadores no ensino de Física. Ens. Pesqui. Educ. Ciênc. (Belo Horizonte) [online], v. 16, n. 3, p. 171-188, 2014. Disponível em: https://bit.ly/2PfV4JT. Acesso em: 10 mai. 2018.

KERSCH, D. F.; MARQUES, R. G. Saímos do cinema de alma lavada: multiletramentos e trabalho interdisciplinar na produção de curtas de acessibilidade midiática. Trab. linguist. apl. [online], v. 55, n. 1, p. 77-99, 2016. Disponível em: https://bit.ly/2FcDNg8. Acesso em: 10 mai. 2018.

KLEIN, J. T. Interdisciplinarity: history, theory e pratice. Detroit: Wayne State University Press, 1990.

KUHN, T. A estrutura das revoluções científicas. São Paulo: Perspectiva, 1989.

LÉTOURNEAU, A. La transdisciplinarité considéréeen général et en sciences de l'environnement. Vertigo - la revue électronique em sciences de l'environnement, v. 8, n. 2, out. 2008. Disponível em: https://bit.ly/2PQeO6e. Acesso em: 29 set. 2018.

LIMA, J. C.; CORTES, S. M. V. A sociologia no Brasil e a interdisciplinaridade nas ciências sociais. Civitas, Porto alegre, v. 13, n. 3, p. 416-435, 2013. Disponível em: http://revistaseletronicas.pucrs.br/ojs/index.php/civitas/article/view/16522. Acesso em: 20 de ago. 2019.

LINS, D. Mangue's school ou por uma pedagogia rizomática. Educação \& Sociedade, Campinas, v. 26, n. 93, p. 1229-1256, 2005. Disponível em: https://bit.ly/2JQ3vpm. Acesso em: 27 set. 2018.

MALDONADO-TORRES, N. Transdisciplinaridade e decolonialidade. Soc. estado. [online], v. 31, n. 1, p. 75-97, 2016. Disponível em: https://bit.ly/2PmtsTD. Acesso em: 10 mai. 2018.

MALUF, R. S. Atribuindo sentido(s) à noção de desenvolvimento econômico. Estudos Sociedade e Agricultura, n. 15, p. 36-56, out. 2000. Disponível em: https://bit.ly/2z7uloR. Acesso em: 20 out. 2018.

MENDOZA, N. A. La UAM-Lerma y su modelo educativo: lo organizacional y el ejercicio interdisciplinar en un espacio universitario. Sociológica (Méx.) [online], v. 31, n. 88, p. 141-166, 2016. Disponível em: https://bit.ly/2qEdBkp. Acesso em: 10 mai. 2018.

MORIN, E. A cabeça bem-feita: repensar a reforma, reformar o pensamento. $8^{a}$ ed. Rio de Janeiro: Bertrand Brasil, 2003.

Introdução ao Pensamento Complexo. Porto Alegre: Sulina, 2006.

Os setes saberes necessários à educação do futuro. Tradução de Catarina Eleonora F. Silva e Jeanne Sawaya. São Paulo: Cortez, 2000.

PHILIPPI JR, A.; FERNANDES, V. Práticas da Interdisciplinaridade no Ensino e na Pesquisa. Barueri, São Paulo: Manole, 2015. 
PIAGET, J. Pensée égocentrique et pensée sociocentrique. Cahiers Vilfredo Pareto, n. 14, p. 148-160, 1976.

PIMENTEL, E. C.; VASCONCELOS, M. V. L.; RODARTE, R. S.; PEDROSA, C. M. S.; PIMENTEL, F. S. C. Ensino e Aprendizagem em Estágio Supervisionado: Estágio Integrado em Saúde. Rev. bras. educ. med. [online], v. 39, n. 3, p. 352-358, 2015. Disponível em: https://bit.ly/2FdTiV8. Acesso em: 10 mai. 2018.

POMBO, O. Interdisciplinaridade e integração dos saberes. Liinc em Revista, v. 1, n. 1, p. 3-15, 2005. Disponível em: https://bit.ly/2zzCWji. Acesso em: 29 set. 2018.

POMPEO, D. A.; ROSSI, L. A.; GALVAO, C. M. Revisão integrativa: etapa inicial do processo de validação de diagnóstico de enfermagem. Acta paul. enferm. [online], v. 22, n. 4, p. 434-438, 2009. Disponível em: encurtador.com.br/wTZ17. Acesso em: 29 out. 2018.

RAYNAULT, C. Interdisciplinaridade: mundo contemporâneo, complexidade e desafios à produção e à aplicação de conhecimentos. In: PHILIPPI JR., A.; SILVA NETO, A. J.

Interdisciplinaridade em ciência, tecnologia e inovação. Barueri, SP: Manole, 2011. p. 69105.

ROCHA, P. A. M. Educação Holística: desafio a educadores e educadoras da nova era. Paulo Afonso: Fonte Viva, 2010.

RUEDA ORTIZ, R.; RIOS GARCIA, M. Doctorados en ciencias sociales: epistemologías y políticas de inclusión. Nómadas, Bogotá, n. 44, p. 45-63, Jan./June 2016. Disponível em: encurtador.com.br/devxT. Acesso em: 02 out. 2018.

SAAVEDRA-CANTOR, C. J.; MUÑOZ-SÁNCHEZ, A. I.; ANTOLÍNEZ-FIGUEROA, C.; RUBIANO-MESA, Y. L. Semilleros de investigación: desarrollos y desafíos para la formación en pregrado. Educ.educ. [online], v. 18, n. 3, p. 391-407, 2015. Disponível em: https://bit.ly/2OyjyZq. Acesso em: 10 mai. 2018.

SANCHO, L. G.; SILVA, N. E. K. Descortinando o acesso aos serviços de saúde na perspectiva da interdisciplinaridade: debate de ideias. Physis [online], v. 23, n. 2, p. 371-391, 2013. Disponível em: https://bit.ly/2DwW32f. Acesso em: 10 mai. 2018.

SANTOS, C. A.; VALEIRAS, N. Currículo interdisciplinar para licenciatura em ciências da natureza. Rev. Bras. Ensino Fís. [online], v. 36, n. 2, p. 1-12, 2014. Disponível em: https://bit.ly/2PTdZtG. Acesso em: 10 mai. 2018.

SHIVA, V. Monoculturas da mente: perspectivas da biodiversidade e da biotecnologia. Tradução: Dinah de Abreu Azevedo. São Paulo: Gaia, 2003.

SHULMAN, L. S. Those who understand: knowledge growth in teaching. Educational Researcher, Washington, v. 15, n. 2, p. 4-14, 1986.

SOMMERMAN, A. A Interdisciplinaridade e a Transdisciplinaridade como novas formas de conhecimento para a articulação de saberes no contexto da ciência e do conhecimento em geral: Contribuição para os campos da Educação, da Saúde e do Meio Ambiente (2012). 1. v Tese (Doutorado em Difusão do Conhecimento) - Faculdade de Educação. Universidade Federal da Bahia. 2012. 
SOUSA, I. F.; BASTOS, P. R. H. O. Interdisciplinaridade e formação na área de Farmácia. Trab. educ. saúde [online], v. 14, n. 1, p. 97-117, 2016. Disponível em: https://bit.ly/2Pi675b. Acesso em: 10 mai. 2018.

SOUZA, M. T.; SILVA, M. D.; CARVALHO, R. Integrative review: what is it? How to do it? Einstein (São Paulo), vol. 8, n. 1, p. 102-106, Mar. 2010. Disponível em: http://www.scielo.br/pdf/eins/v8n1/pt_1679-4508-eins-8-1-0102.pdf. Acesso em: 10 fev. 2019

STADLER, J. P.; HUSSEIN, F. R. G. S. O perfil das questões de ciências naturais do novo Enem: interdisciplinaridade ou contextualização? Ciênc. educ. (Bauru) [online], v. 23, n. 2, p. 391-402, 2017. Disponível em: https://bit.ly/2z09NhP. Acesso em: 10 mai. 2018.

TARDIF, M. Saberes docentes e formação profissional. 1. ed. Petrópolis: Vozes, 2002.

TAVARES, M.; GOMES, S. Fundamentos epistemológicos da matriz institucional dos novos modelos de educação superior no Brasil: uma abordagem qualitativa dos documentos institucionais da Universidade Federal do ABC. Educ. Soc. [online], v. 39, n. 144, p. 634-651, 2017. Disponível em: https://bit.ly/2JOIXh3. Acesso em: 10 mai. 2018.

TOASSI, R. F. C.; LEWGOY, A. M. B. Práticas Integradas em Saúde I: uma experiência inovadora de integração intercurricular e interdisciplinar. Interface (Botucatu) [online], v. 20, n. 57, p. 449-461, 2016. Disponível em: https://bit.ly/2JOIQ57. Acesso em: 10 mai. 2018.

VARGAS-D'UNIAM, J.; LANDAYETA, E. C.; VELARDE, V. V. Innovación en la docencia universitaria. Una propuesta de trabajo interdisciplinario y colaborativo eneducación superior. Educación, v. 25, n. 48, p. 67-84, 2016. Disponível em: https://bit.ly/2Dv5zCL. Acesso em: 10 mai. 2018.

VASEN, F.; VIENNI, B. La institucionalización de la interdisciplina en la universidad latino americana: experiencias y lecciones de Uruguay y Argentina. Avaliação [online], v. 22, n. 2, p. 544-565, 2017. Disponível em: https://bit.ly/2FefE8S. Acesso em: 10 mai. 2018.

VENTURA, D. F. L.; LINS, M. A. D. T. Educação superior e complexidade: integração entre disciplinas no campo das relações internacionais. Cad. Pesqui. [online], v. 44, n. 151, p. 104131, 2014. Disponível em: https://bit.ly/2DvfFDO. Acesso em: 10 mai. 2018.

WANDERLEY, L. E. W. Realismo utópico: o público e o intertransdisciplinar. Estud. av. [online], v. 27, n. 78, p. 121-132, 2013. Disponível em: https://bit.ly/2PkQ5Yc. Acesso em: 10 mai. 2018.

WENGER, E. Comunidades de práctica: Aprendizaje, significado e identidad. Barcelona: Ed. Paidós, 2001.

Communities of practice: learning, meaning and identity. Cambridge: Cambridge University Press, 1998.

XAVIER, A. M.; STEIL, L. J.; MENA-CHALCO, J. P. (Inter)disciplinaridade e transversalidades: o projeto de formação superior da Universidade Federal do ABC. Ciênc. educ. (Bauru) [online], v. 23, n. 2, p. 373-390, 2017. Disponível em: https://bit.ly/2PMeDsB. Acesso em: 10 mai. 2018. 
Submetido: 24/07/2019

Aprovado: 17/05/2020 